\title{
ORIGINAL ARTICLE Epidermal growth factor-induced ANGPTL4 enhances anoikis resistance and tumour metastasis in head and neck squamous cell carcinoma
}

\author{
Y-H Liao' ${ }^{1}$ K-H Chiang ${ }^{2}$, J-M Shieh ${ }^{2}$, C-R Huang ${ }^{1,3}$, C-J Shen ${ }^{1}$, W-C Huang ${ }^{1,4}$ and B-K Chen ${ }^{1,5,6}$
}

\begin{abstract}
Epidermal growth factor (EGF) is important for cancer cell proliferation, angiogenesis and metastasis in many types of cancer. However, the mechanisms involved in EGF-induced head and neck squamous cell carcinoma (HNSCC) metastasis remain largely unknown. In this study, we reveal that angiopoietin-like 4 (ANGPTL4) plays an important role in the regulation of EGF-induced cancer metastasis. We showed that EGF-induced ANGPTL4 expression promoted anoikis resistance and cancer cell migration and invasion in HNSCC. In addition, depletion of ANGPTL4 inhibited EGF-induced cancer cell invasion. Autocrine production of EGFinduced ANGPTL4 regulated the expression of matrix metalloproteinases (MMPs). The induction of MMP-1 gene expression by ANGPTL4-activated integrin $\beta 1$ signalling occurred through the AP-1 binding site in the MMP-1 gene promoter. Furthermore, downregulation of MMP-1 impeded EGF- and recombinant ANGPTL4-enhanced HNSCC cell migration and invasion. Depletion of ANGPTL4 significantly blocked EGF-primed extravasation and metastatic seeding of tumour cells and MMP-1 expression in lungs. However, no effect of ANGPTL4 on tumour growth was observed. These results suggest that EGF-induced expression and autocrine production of ANGPTL4 enhances HNSCC metastasis via the up-regulation of MMP-1 expression. Inhibition of ANGPTL4 expression may be a potential strategy for the treatment of EGFR-mediated HNSCC metastasis.
\end{abstract}

Oncogene (2017) 36, 2228-2242; doi:10.1038/onc.2016.371; published online 31 October 2016

\section{INTRODUCTION}

Head and neck squamous cell carcinoma (HNSCC) is the most common type of cancer worldwide. Among men, HNSCC is the eighth leading type of cancer among the estimated new cancer cases in the United States. ${ }^{1}$ HNSCC represents a group of highly heterogeneous tumours. Over the last few decades, despite advances in treatment, the mortality rate of HNSCC has not significantly changed. ${ }^{2}$ Metastasis is the most important contributor to the mortality of cancer patients. The pathogenesis of cancer metastasis involves several processes, including the loss of cellular adhesion, increased cell invasion, survival in the circulation during extravasation and eventual colonization of distant organs. ${ }^{3}$

Tumour cells that survive in the circulation are characterized by anoikis resistance. ${ }^{4}$ Anoikis is a type of cell death that is induced upon cell detachment from the extracellular matrix, and it is a key mechanism in the maintenance of tissue homeostasis and development. ${ }^{5}$ Anoikis can occur through the activation of the death receptor and/or mitochondrial apoptosis pathway, resulting in caspase- 3 activation. Defects in either of these pathways render malignant cells resistant to anoikis. ${ }^{4,6}$ Up-regulation of antiapoptotic proteins such as $\mathrm{Bcl}-2, \mathrm{BCl}-\mathrm{X}_{\mathrm{L}}, \mathrm{Bax}, \mathrm{Bim}$ and BAD, and activation of integrins and the EGFR activated pro-survival PI3KAkt pathway all contribute to anoikis resistance. ${ }^{6,7}$ For example, the expression of cytokines confers anoikis resistance to tumour cells through the activation of survival pathways. Hepatocyte growth factor inhibits anoikis and mediates survival in HNSCC by activating the extracellular signal-regulated kinase (ERK)-dependent AP-1 signalling pathway. ${ }^{8}$ E-cadherin-mediated EGFR activation has also been demonstrated to protect HNSCC from anoikis and maintain cell survival. ${ }^{9}$ In addition, both hepatocyte growth factor and epidermal growth factor (EGF) play important roles in the progression and metastasis of HNSCC. ${ }^{10-12}$ Cytokines such as CXCL8 enhance the resistance of colorectal cancer cells to anoikis by increasing TOPK and activating AKT and ERK. ${ }^{13}$ IL-6 significantly augments STAT3-mediated anoikis resistance in pancreatic cancer cell lines. These results support the possibility that growth factors and cytokines enhance tumour metastasis by enhancing anoikis resistance of cancer cells. However, the mechanism involved in EGF-mediated regulation of anoikis resistance that leads to enhanced HNSCC metastasis remains unclear.

Angiopoietin-like 4 (ANGPTL4), a secreted protein consisting of $\mathrm{N}$-terminal and C-terminal domains, is a member of the angiopoietin family, and it plays important roles in lipid and glucose metabolism. ${ }^{14}$ Interestingly, up-regulation of ANGPTL4 has been observed in various types of human cancers, including colorectal cancer, breast cancer, esophageal SCC and oral tongue SCC. The expression of ANGPTL4 in tumours is highly associated with metastasis. For example, constitutive activation of EGFR (EGFRvIII) induces ANGPTL4 expression through the ERK/c-Myc pathway and promotes tumour angiogenesis in malignant gliomas. ${ }^{15}$ ANGPTL4 induction by prostaglandin E2 $\left(\mathrm{PGE}_{2}\right)$ under hypoxic conditions promotes colorectal cancer progression. ${ }^{16}$

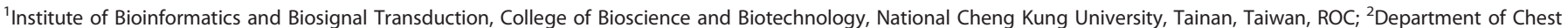

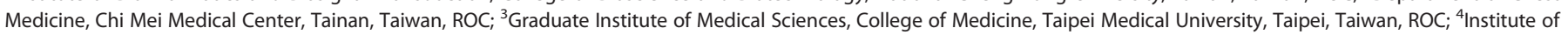

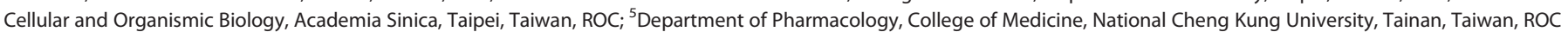

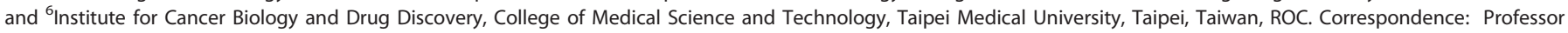
W-C Huang or Professor B-K Chen, Institute of Bioinformatics and Biosignal Transduction, National Cheng Kung University, No. 1, University Road, Tainan 701, Taiwan. 
ANGPTL4 promotes oral squamous cell carcinoma metastasis by stimulating cell invasion. ${ }^{17}$ ANGPTL4 induced by TGF $\beta$ via the Smad signalling pathway promotes breast cancer metastasis. ${ }^{18}$ Recent reports indicate that the effect of ANGPTL4 on tumour metastasis may be mediated by integrin activation. ANGPTL4 stimulates integrin-dependent survival signals through the activation of NADPH oxidase 1 (Nox1), mimics anchorage conditions and confers anoikis resistance to tumour cells by regulating oncogenic reactive oxygen species (ROS). ${ }^{19}$ Tumourderived C-terminal ANGPTL4 (cANGPTL4) binds to integrin a5 $\beta 1$ and activates the downstream PAK/Rac signalling pathway, resulting in endothelial disruption in TGF $\beta$-enhanced lung metastasis of breast cancer. ${ }^{18,20}$ However, previous studies have shown that ANGPTL4 inhibits angiogenesis and prevents metastasis, ${ }^{21,22}$ highlighting a controversial effect of ANGPTL4 on tumour metastasis. While the expression of ANGPTL4 is associated with angiogenesis and vascular permeability, the expression of ANGPTL4 or matrix metalloproteinases (MMPs) is correlated with cancer survival and invasion. ${ }^{23,24}$ Interestingly, the co-expression of ANGPTL4 and MMPs has also been correlated with matrix remodelling in cartilage degradation and chondrogenic differentiation. ${ }^{25,26}$ The ANGPTLs, such as ANGPTL1, repress lung cancer cell migration and invasion by regulating the integrin $a 1 \beta 1 / F A K / E R K / S P 1 / m i R-630 / S L U G$ signalling axis. ${ }^{27}$ However, whether the expression of ANGPTL4 is associated with epithelialto-mesenchymal transition is still unclear.

In this study, we reveal for the first time that autocrine production of EGF-induced ANGPTL4 in tumour cells not only enhances anoikis resistance but also promotes MMP-1 expression through activation of the integrin $\beta 1$ signalling pathway, resulting in HNSCC metastasis. ANGPTL4 inhibition represents a new strategy for the treatment of EGFR-mediated HNSCC metastasis.

\section{RESULTS}

EGF enhances ANGPTL4 expression in HNSCC

To investigate whether the expression of ANGPTL4 is associated with the activation of EGFR signalling in HNSCC, cells were treated with EGF for varying periods of time. As shown in Figure 1a, EGF
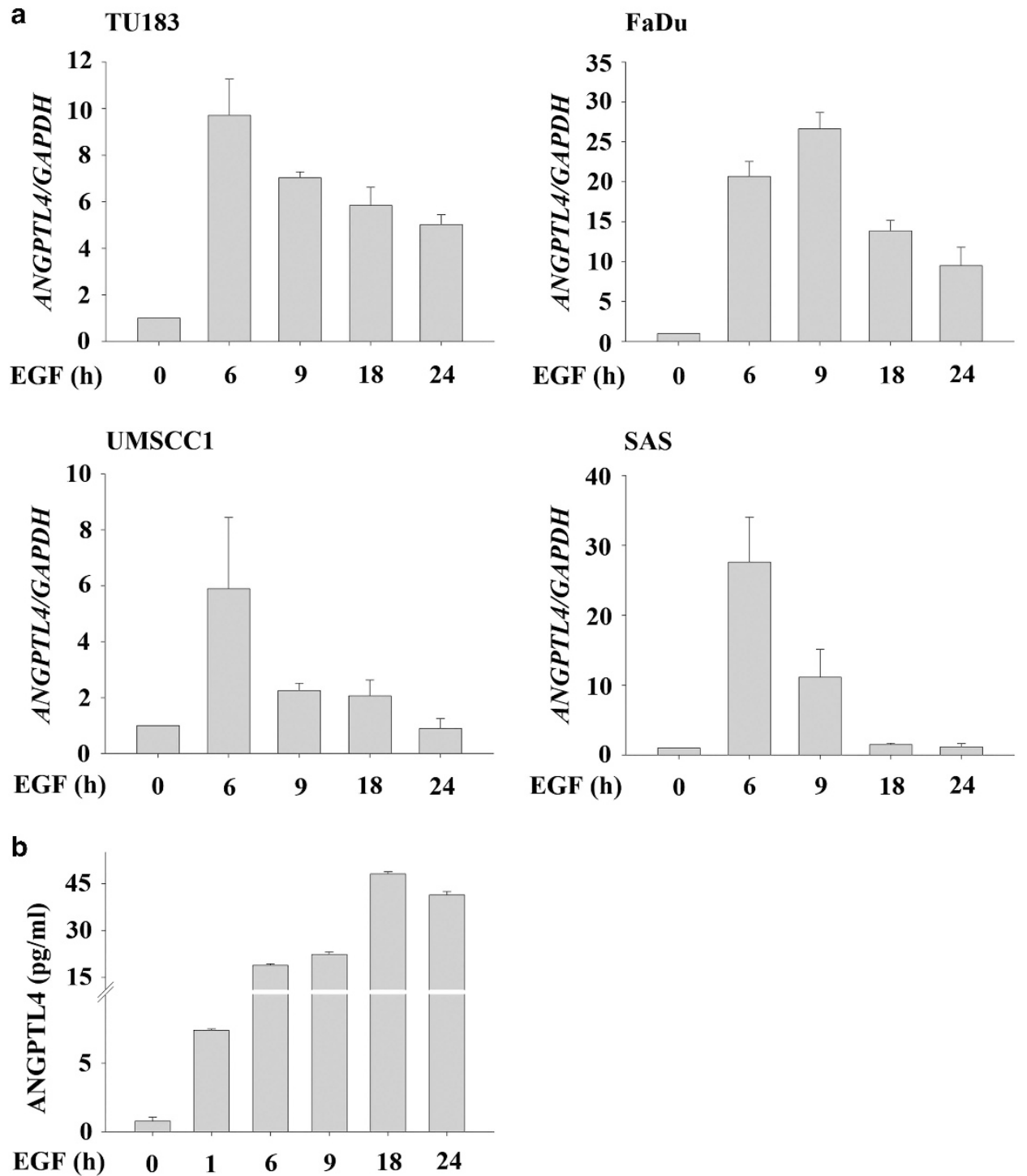

Figure 1. EGF induces expression of ANGPTL4 in HNSCC cell lines. (a) HNSCC cell lines were treated with $50 \mathrm{ng} / \mathrm{ml}$ EGF for the indicated period of time. The expression of ANGPTL4 and GAPDH mRNA was analysed by real-time quantitative PCR. Relative levels of ANGPTL4 were normalized to GADPH. Values are indicated as the mean \pm s.e.m. (b) TU183 cells were treated with $50 \mathrm{ng} / \mathrm{ml}$ EGF for the indicated period of time. Secreted ANGPTL4 was harvested from conditioned medium and detected by ELISA. Values are indicated as the mean \pm s.e.m. 
significantly induced the expression of ANGPTL4 in a timedependent manner in various HNSCC cell lines. To further confirm the induction of ANGPTL4 by EGF, the expression and secretion of ANGPTL4 were examined using an enzyme-linked immunosorbent assay (ELISA). An increase in ANGPTL4 was observed in the conditioned media harvested from EGF-treated cells (Figure 1b). These results suggest that EGF induces the expression and secretion of ANGPTL4 in HNSCC.

a
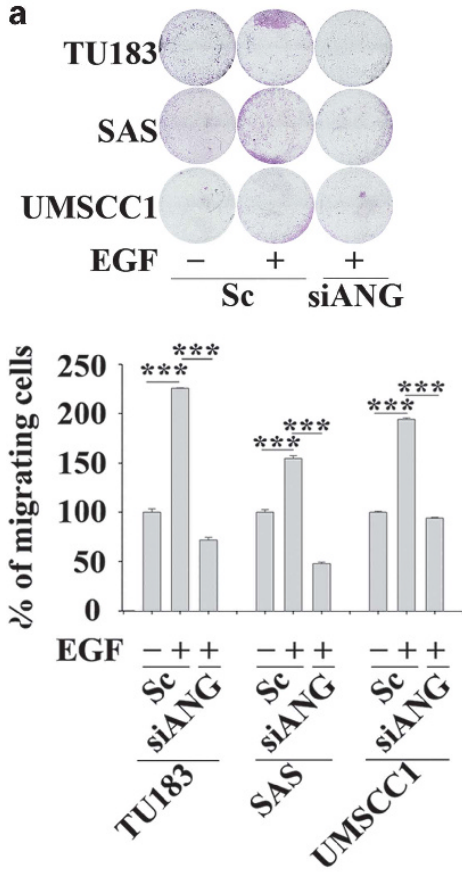

b
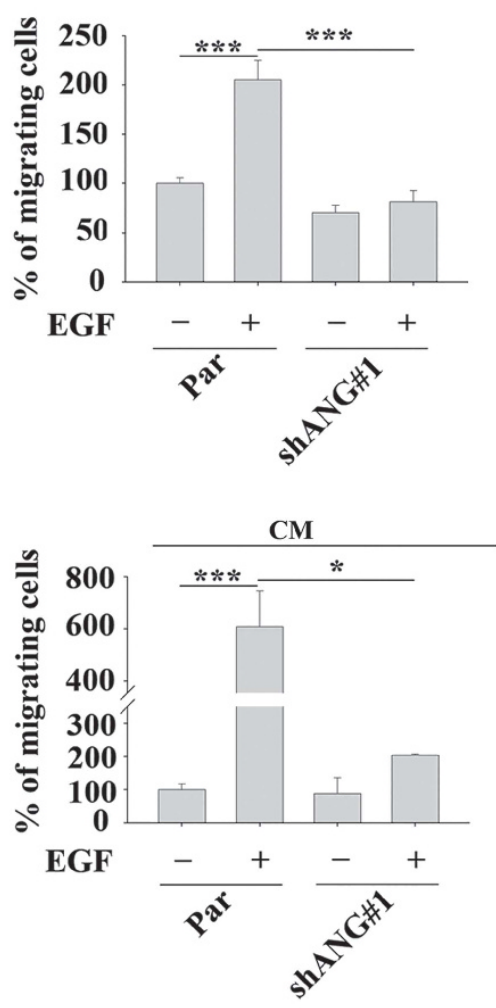

EGF-induced ANGPTL4 promotes HNSCC migration and invasion Recent studies have suggested that although ANGPTL4 mediates TGF $\beta$-induced lung metastasis of breast cancer, ${ }^{18}$ it also inhibits the metastasis of melanoma cells. ${ }^{22}$ These conflicting results indicate that the role of ANGPTL4 in the regulation of cancer metastasis has yet to be clarified for different types of cancer. To better understand the biological significance of EGF-induced ANGPTL4 expression in tumour cells, siRNA targeting ANGPTL4
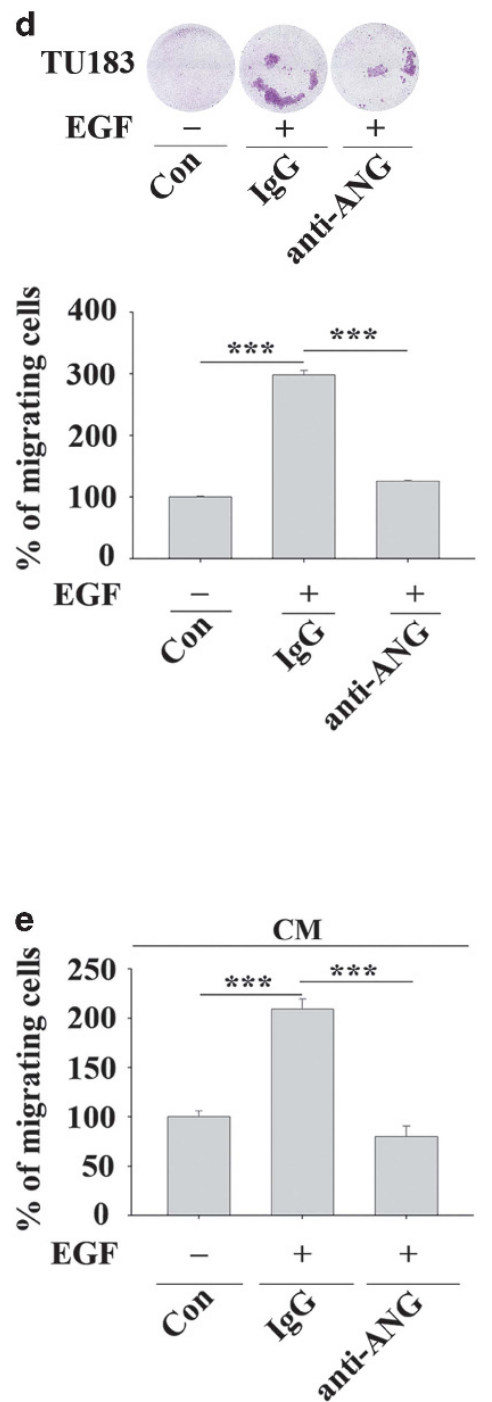

f

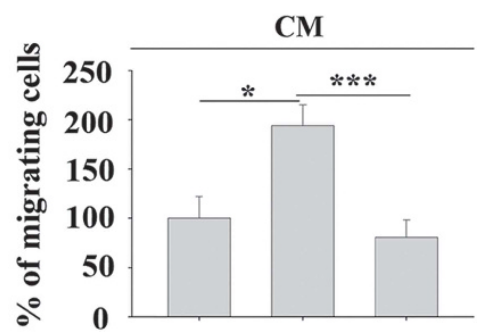

flANGPTL4

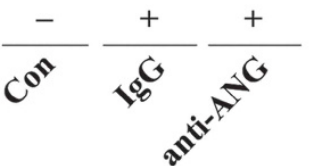


(siANGPTL4) and stable cell lines with ANGPTL4 depleted via shRNA (shANGPTL4) were used. The inhibition of ANGPTL4 expression by gene knockdown was confirmed in EGF-treated cells (Supplementary Figures $1 \mathrm{a}$ and b). The EGF-induced migration of HNSCC cells was reduced in ANGPTL4-knockdown cells (Figures $2 \mathrm{a}$ and $\mathrm{b}$ ). To further confirm that the secretion of EGF-induced ANGPTL4 regulates cell migration, the conditioned media harvested from EGF-treated parental and shANGPTL4 cells were used to treat cancer cells. ANGPTL4 secreted from EGFtreated parental cells, but not shANGPTL4 cells dramatically induced cell migration in a time-dependent manner (Supplementary Figure 1c and Figure 2c). The involvement of ANGPTL4 in the regulation of EGF-induced migration was also examined by disrupting the function of ANGPTL4 with antiANGPTL4 antibodies. The antibody-induced neutralization of ANGPTL4 significantly blocked EGF- and conditioned mediainduced cell migration (Figures $2 d$ and e). In addition, the conditioned media harvested from cells overexpressing ANGPTL4 (Supplementary Figure S1d) also induced tumour cell migration (Figure 2f). However, the cell migration induced by the overexpression of ANGPTL4 was also inhibited by the neutralization of ANGPTL4 in the culture media (Figure 2f). These results suggest that EGF-induced ANGPTL4 regulated HNSCC migration. The contribution of EGF-induced ANGPTL4 to tumour invasion was further investigated. As shown in Figures $3 a$ and $b$, depletion and neutralization of ANGPTL4 inhibited EGF-induced HNSCC cell invasion. Conditioned media harvested from EGF-treated cells induced tumour invasion that was also blocked by siANGPTL4 and neutralization of ANGPTL4 (Figures $3 c$ and d). Inhibition of EGFinduced invasion by siANGPTL4 was reversed when the cells were treated with recombinant ANGPTL4 (Figure 3e). The effect of ANGPTL4 on invasion was further verified using the transendothelial invasion assay. Briefly, endothelial cells were grown until they formed a monolayer on the bottom of a thick layer of extracellular matrix proteins to mimic intravasation. As shown in Figure 3f, EGFinduced invasion was significantly inhibited in shANGPTL4 cells, and the recombinant ANGPTL4 significantly rescued the invasion in ANGPTL4-depleted cells. To further clarify whether ANGPTL4enhanced migration and invasion was correlated with the activation of EGF signalling, the recombinant ANGPTL4 protein was used alone in serum-free cell culture. As shown in Supplementary Figure S2, ANGPTL4 significantly promoted tumour migration and invasion. In summary, these results suggest that EGF-induced expression and secretion of ANGPTL4 promoted HNSCC migration and invasion.
EGF-induced ANGPTL4 promotes tumour-endothelial cell interactions and anoikis resistance

During tumour metastasis, the infiltration of tumour cells into distant locations initially relies on their attachment to blood vessels. Therefore, the ability of EGF-induced ANGPTL4 to promote the interaction between tumour cells and endothelial cells was examined. The enhancement of binding between tumour and endothelial cells was observed in EGF-treated parental but not ANGPTL4-depleted cells (Figure 4a). Although recombinant ANGPTL4 alone produced minor effect on the interaction (Figure 4b), treatment with EGF and ANGPTL4 reversed the inhibition of the tumour-endothelial cell interaction in the ANGPTL4-knockdown cells (Figure 4). In addition, the interaction was also blocked by the neutralization of ANGPTL4 with antiANGPTL4 antibodies (Figure 4b). These results indicated that autocrine production of EGF-induced ANGPTL4 stimulated the binding of tumour cells to endothelial cells, which may enhance the ability of tumour cells to penetrate blood vessels. In addition, to investigate whether EGF-induced ANGPTL4 conferred anoikis resistance to regulate the distal dissemination of metastatic tumour cells, the anchorage-independent survival of tumour cells was examined. As shown in Figure $5 \mathrm{a}$, the secretion of EGFinduced ANGPTL4 in suspension culture was inhibited in shANGPTL4 cells, resulting in the inhibition of EGF-induced anoikis resistance. The reduction in anoikis resistance was reversed by treating shANGPTL4 cells with recombinant CANGPTL4 protein, even CANGPTL4 alone, which produced a minor effect on parental cells (Figure 5a). In addition, EGF-induced anoikis resistance was reduced by the neutralization of ANGPTL4 (Figure 5a). The depletion of ANGPTL4 reduced EGF-enhanced cell survival in suspension culture (Figures $5 \mathrm{~b}$ and $\mathrm{c}$ ). To further examine whether EGF-induced ANGPTL4 regulated the interaction between anoikis resistant cells and endothelial cells, siRNA was used to deplete ANGPTL4 in suspension cells. The knockdown of ANGPTL4 significantly repressed anoikis-resistant tumour-endothelial cell interactions (Figure 5d). Notably, the ability of EGF-promoted anoikis-resistant cells to undergo transendothelial invasion was also reduced by the depletion of ANGPTL4 (Figure 5e). These results revealed that EGF-induced ANGPTL4 promoted anoikis resistance and interactions with endothelial cells, which may enhance metastasis.

\section{Expression of c-Jun is essential for ANGPTL4-induced MMP-1 expression}

Based on the observation that ANGPTL4 expression was essential for EGF-enhanced cancer cell migration and invasion, we next investigated the mechanisms involved in ANGPTL4-regulated

Figure 2. EGF-induced ANGPTL4 enhances HNSCC migration. The migratory properties of HNSCC cells were analysed using a transwell assay as described in 'Materials and methods'. (a) TU183 cells were transfected with or without 50 nM ANGPTL4 siRNA oligonucleotides (siANG) by lipofection. After treatment with $50 \mathrm{ng} / \mathrm{ml}$ EGF for $24 \mathrm{~h}$, migrating cells were fixed, stained with crystal violet and examined using a microscope (upper panel). Original magnification, $\times 20$. Cells were stained with crystal violet, solubilized with acetic acid and absorbance (OD, $595 \mathrm{~nm}$ ) was measured in a microplate reader (lower panel). Values are the mean \pm s.e.m. (b) Parental (Par) and shANGPTL4 (shANG) TU183 cells were treated with $50 \mathrm{ng} / \mathrm{ml}$ EGF for $24 \mathrm{~h}$. Migrating cells were fixed and stained with crystal violet, solubilized with acetic acid and absorbance $(O D, 595 \mathrm{~nm}$ ) was measured in a microplate reader. Values are the mean \pm s.e.m. (c) TU183 cells were treated with conditioned medium (CM) collected from EGF-treated parental (Par) and shANGPTL4 (shANG) TU183 cells. Migrating cells were fixed and stained with crystal violet, solubilized with acetic acid and absorbance $(O D, 595 \mathrm{~nm})$ was measured in a microplate reader. Values are the mean \pm s.e.m. (d) TU183 cells were treated with $10 \mu \mathrm{g} / \mathrm{ml}$ anti-ANGPTL4 antibodies (anti-ANG), $10 \mu \mathrm{g} / \mathrm{ml}$ immunoglobulin G (IgG) and $50 \mathrm{ng} / \mathrm{ml}$ EGF for $24 \mathrm{~h}$. Migrating cells were fixed, stained with crystal violet and examined using a microscope (upper panel). Original magnification, $\times 20$. The crystal violet solubilized with acetic acid and absorbance $(O D, 595 \mathrm{~nm}$ ) was measured in a microplate reader (lower panel). Values are the mean \pm s.e.m. (e) CM was collected from TU183 cells treated with $50 \mathrm{ng} / \mathrm{ml}$ EGF. TU183 cells were then treated with $10 \mu \mathrm{g} / \mathrm{ml}$ anti-ANGPTL4 antibodies (antiANG), $10 \mu \mathrm{g} / \mathrm{ml}$ immunoglobulin G (lgG) and CM for $24 \mathrm{~h}$. Migrating cells were fixed and stained with crystal violet, solubilized with acetic acid and absorbance $(O D, 595 \mathrm{~nm}$ ) was measured in a microplate reader. Values are the mean \pm s.e.m. (f) CM was collected from flANGPTL4overexpressing TU183 cells. TU183 cells were then treated with $10 \mu \mathrm{g} / \mathrm{ml}$ anti-ANGPTL4 antibodies (anti-ANG), $10 \mu \mathrm{g} / \mathrm{ml}$ immunoglobulin G $(\mathrm{IgG})$ and CM for $24 \mathrm{~h}$. Migrating cells were fixed and stained by crystal violet, solubilized with acetic acid and absorbance (OD, $595 \mathrm{~nm})$ was measured in a microplate reader. Values are the mean \pm s.e.m. ${ }^{*} P<0.05 ;{ }^{* * *} P<0.005$. 
cell metastasis. Although no changes in fibronectin, E-cadherin, $\mathrm{N}$-cadherin, slug or twist were observed in EGF-treated cells, the expression levels of MMPs, including MMP-1, MMP-3, MMP-9 and MMP-10, were increased (Figure 6a). Previous studies have shown that the expression of MMPs is dependent on ANGPTL4 levels and correlates with cancer metastasis. ${ }^{23,24}$ To further confirm whether ANGPTL4 was required for EGF-induced MMP expression, the effects of ANGPTL4 knockdown on gene expression were examined. Indeed, depletion of ANGPTL4 inhibited EGF-induced MMP expression (Figure $6 \mathrm{~b}$ and Supplementary Figures S3a and b). EGF-enhanced MMP-1 promoter activity was also repressed either following knockdown of ANGPTL4 (Figure 6c) or neutralization of the protein using anti-ANGPTL4 antibodies (Figure $6 \mathrm{~d}$ ). Inhibition of MMP-1 promoter activity was reversed following treatment with EGF and recombinant CANGPTL4 in ANGPTL4-depleted cells (Figures $6 \mathrm{c}$ and d). In addition, EGFinduced MMP-1 protein expression and enzymatic activity were also reduced in ANGPTL4-depleted cells (Figure 6e). These results suggested that the expression of ANGPTL4 was essential for EGFinduced MMP-1 expression. Although we confirmed that MMP expression was regulated by ANGPTL4, the mechanism involved in ANGPTL4-regulated expression of MMPs such as MMP-1 remains a
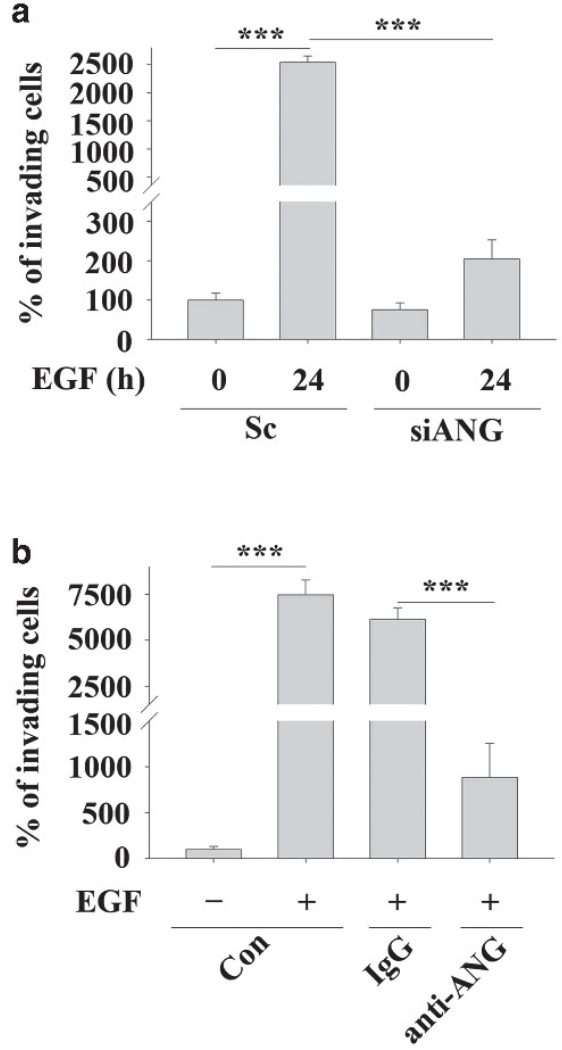

C
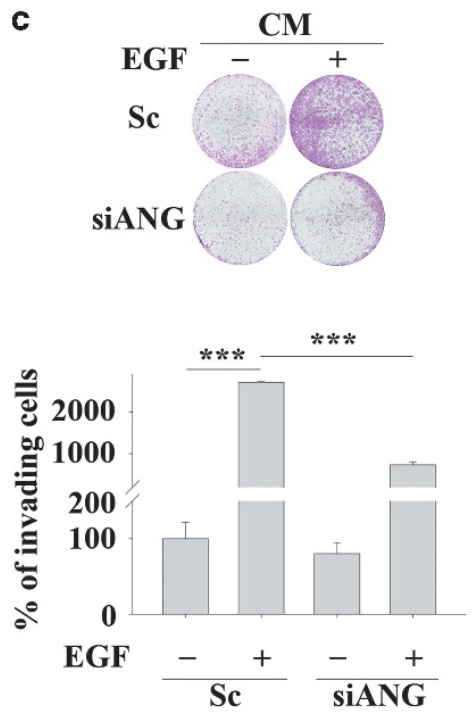

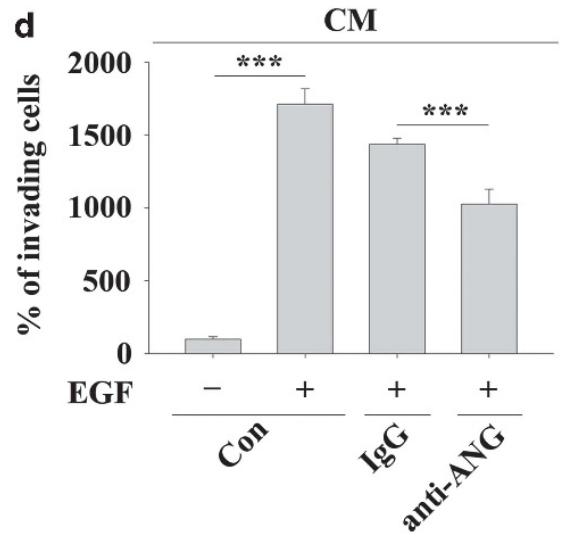

e

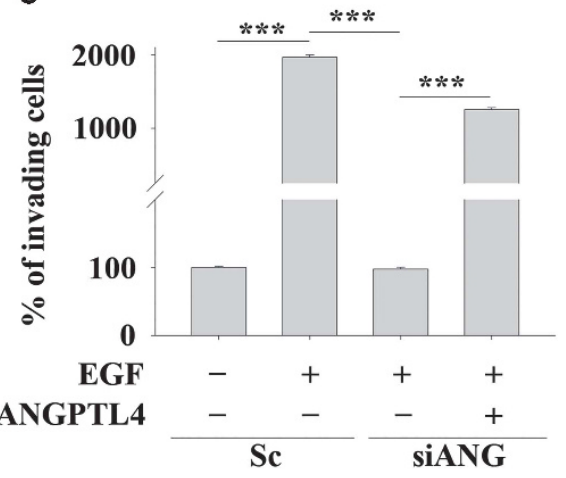

f
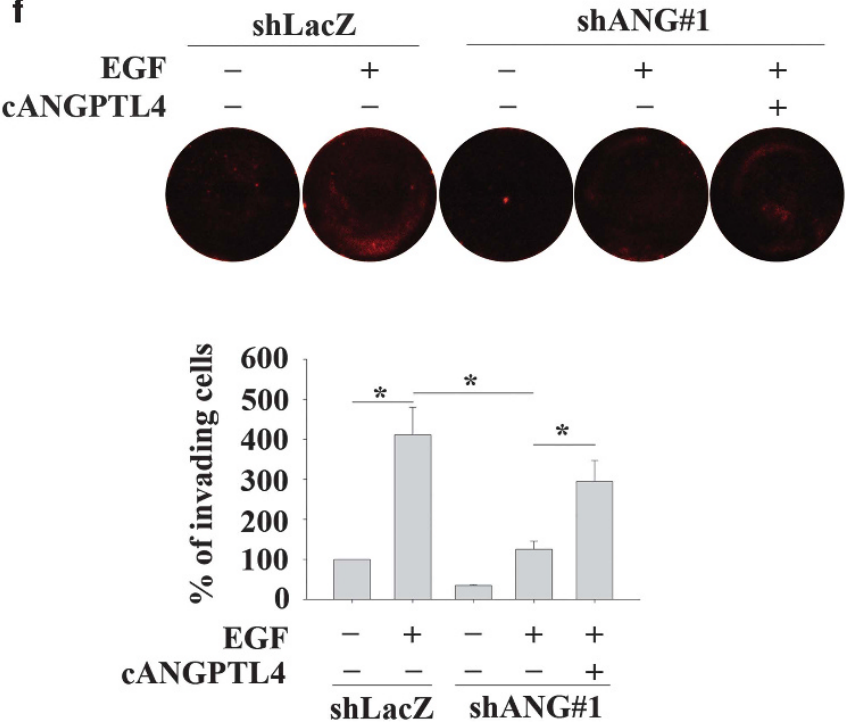
unclear. Previous studies have shown that the activated c-Jun/Fra-1 complex binds to the AP-1-binding site of the MMP-1 promoter to enhance MMP-1 gene expression. ${ }^{28}$ To further clarify whether AP-1-binding sites mediate ANGPTL4-regulated MMP-1 promoter activity, a promoter containing mutated AP-1-binding sites was constructed (Figure 7a). As shown in Figure 7b, both conditioned media harvested from EGF-treated and ANGPTL4 overexpressing cells significantly induced MMP-1 promoter activity. However, the induction was dramatically inhibited with the mutated constructs ( $m t 1$ and $m t 2$ ). These results indicated that the AP-1-binding sites located in the -430 to $-426 \mathrm{bp}$ region and -131 to $-126 \mathrm{bp}$ region were essential for EGF- and ANGPTL4-induced MMP-1 expression. Next, we examined whether c-Jun was essential for ANGPTL4-induced MMP-1 expression. As shown in Supplementary Figure $S 3 c$ and Figure $7 c, E G F$ and ANGPTL4 induced the activation of c-Jun; however, the depletion of c-Jun dramatically inhibited ANGPTL4-induced MMP-1 promoter activity. In addition, overexpression of c-Jun also enhanced promoter activity, but the induction was repressed in constructs with mutated AP-1 site (Figure 7c). These results suggest that ANGPTL4-induced MMP-1 expression was regulated by the c-Jun signalling pathway.

Integrin $\beta 1$ is essential for EGF- and ANGPTL4-induced MMP-1 expression and tumour-endothelial cell interactions

The binding of ANGPTL 4 to integrin a5 $\beta 1$ has been reported to be essential for the activation of Rac signalling and to enhance the permeability of blood vessels. ${ }^{29}$ Therefore, we further verified the requirement of integrin $\beta 1$ for EGF- and ANGPTL4-induced MMP-1 expression. As shown in Figures $8 a$ and $b$, either the integrin antagonist (Arg-Gly-Asp) peptides or knockdown of integrin $\beta 1$ inhibited EGF- and ANGPTL4-induced MMP-1 promoter activity. The inhibition of integrin also blocked EGF- and ANGPTL4-induced tumour-endothelial cell interactions (Figure $8 \mathrm{c}$ ). These results suggest that activation of the integrin $\beta 1$ signalling pathway was at least partially essential for EGF- and ANGPTL4-induced MMP-1 expression and tumour-endothelial cell interactions.

\section{The EGF/ANGPTL4/MMP-1 axis promotes HNSCC metastasis}

To further confirm the role of the EGF/ANGPTL4/MMP-1 axis in tumour metastasis, the effect of MMP-1 knockdown on EGF- and ANGPTL4-induced cell migration and invasion was studied. The results showed that ANGPTL4-induced migration and invasion were blocked in MMP-1 knockdown cells (Figures 9a and b). The synergistic effect of EGF and ANGPTL4 on migration and invasion was also reduced in MMP-1 knockdown cells (Figures 9a and b). Next, we examined whether ANGPTL4 was essential for
EGF-enhanced metastasis in vivo by injecting EGF-pretreated parental and shANGPTL4 cells into the tail veins of mice. As shown in Figure 9c, increased metastatic nodules in lung tissues were found in mice injected with EGF-primed parental cells. Consistent with the observations in the transendothelial invasion assay, depletion of ANGPTL4 inhibited the metastatic seeding of EGFprimed tumour cells in the lungs. In addition, the expression of MMP-1 protein in lung tissues was observed in EGF-primed parental but not shANGPTL4 cells (Figure 9c). To further clarify whether the reduction of metastatic nodules of ANGPTL4depleted cells was associated with the inhibition of tumour growth, tumour cell proliferation was examined in parental and shANGPTL4 cells. Cell proliferation and division rates remained unchanged between parental and shANGPTL4 cells (Supplementary Figures S4a and b). Furthermore, the growth of shANGPLT4 and parental cells in the subcutaneous space of mice did not differ (Supplementary Figure 4c). Again, transient knockdown of ANGPTL4 by siRNA was confirmed. The results suggested that the effect of siRNA oligonucleotides on ANGPTL4 inhibition was presented within $48 \mathrm{~h}$ in EGF-treated cells (Supplementary Figure 4d). However, ANGPTL4 siRNA also significantly inhibited EGF-primed pulmonary metastasis (Figure 9c). In addition, the extravasation assay ${ }^{30-32}$ revealed that EGF-promoted tumour cell penetration of blood vessels was significantly inhibited in ANGPTL4-depleted cells (Figure 9d). These results revealed that ANGPTL4-regulated pulmonary metastasis occurred via activation of tumour extravasation but not tumour growth. Taken together, induction of the ANGPTL4/MMP-1 axis was essential for EGFinduced HNSCC metastasis. However, depletion of ANGPTL4 was not associated with tumour growth.

\section{DISCUSSION}

Although the role of ANGPTL4 in the regulation of lipid metabolism is clear, the function of ANGPTL4 in the regulation of metastasis remains controversial. For example, ANGPTL4 prevents Lewis lung carcinoma metastasis through the inhibition of vascular permeability and tumour cell motility and invasiveness. ${ }^{22}$ However, the induction of ANGPTL4 via the Smad signalling pathway by TGF $\beta$ promotes breast tumour metastasis. ${ }^{18}$ Therefore, to further clarify the function of ANGPTL4 in HNSCC metastasis, we examined the effect of ANGPTL4 on EGF-induced HNSCC metastasis. For the first time, we revealed that tumourderived ANGPTL4 promoted HNSCC migration and invasion. In an in vivo assay, penetration of blood vessels for metastatic seeding of the lungs by EGF-primed tumour cells was inhibited by the depletion of ANGPTL4. Previous studies have also indicated that tumour-derived ANGPTL4 promotes cell survival and tumour

Figure 3. EGF-induced ANGPTL4 enhances HNSCC invasion. The invasive properties of the cells were examined using an invasion assay as described in 'Materials and methods'. (a) TU183 cells were transfected with $50 \mathrm{nM}$ ANGPTL4 siRNA oligonucleotides (siANG) and scramble siRNA (Sc) by lipofection. Following treatment with $50 \mathrm{ng} / \mathrm{ml}$ EGF for $24 \mathrm{~h}$, the invading cells were fixed and stained with crystal violet, solubilized with acetic acid and absorbance $(O D, 595 \mathrm{~nm})$ was measured in a microplate reader. Values are the mean \pm s.e.m. (b) TU183 cells were treated with $10 \mu \mathrm{g} / \mathrm{ml}$ anti-ANGPTL4 antibodies (anti-ANG), $10 \mu \mathrm{g} / \mathrm{ml} \mathrm{lgG} \mathrm{and} 50 \mathrm{ng} / \mathrm{ml}$ EGF for 48 h. The invading cells were fixed and stained by crystal violet, solubilized with acetic acid and absorbance (OD, $595 \mathrm{~nm}$ ) was measured in a microplate reader. Values are the mean \pm s.e.m. (c and d) TU183 cells were transfected with $50 \mathrm{nM}$ ANGPTL4 siRNA oligonucleotides (siANG) and scramble siRNA (Sc) by lipofection, and CM was collected from EGF-treated or non-treated cells. TU183 cells were then treated with $10 \mu \mathrm{g} / \mathrm{ml}$ anti-ANGPTL4 antibodies (anti-ANG), $10 \mu \mathrm{g} / \mathrm{ml}$ immunoglobulin G (lgG) and CM for $48 \mathrm{~h}$. The invading cells were fixed, stained with crystal violet and examined using a microscope (c, upper panel). Original magnification, $\times 20$. The crystal violet solubilized with acetic acid and absorbance $(O D$, $595 \mathrm{~nm}$ ) was measured in a microplate reader (c, lower panel and d). Values are the mean \pm s.e.m. (e) TU183 cells were transfected with $50 \mathrm{nM}$ ANGPTL4 siRNA oligonucleotides (siANG) and scramble siRNA (Sc) by lipofection, and then treated with $50 \mathrm{ng} / \mathrm{ml}$ EGF and $250 \mathrm{ng} / \mathrm{ml}$ recombinant C-terminal ANGPTL4 (CANGPTL4) for $48 \mathrm{~h}$. The invading cells were fixed and stained with crystal violet, solubilized with acetic acid and absorbance (OD, $595 \mathrm{~nm}$ ) was measured in a microplate reader. Values are the mean \pm s.e.m. (f) The transendothelial invasion of cancer cells was performed as described in 'Materials and methods'. Endothelial cells were grown to form a monolayer on the bottom of a thick layer of extracellular matrix proteins to mimic intravasation in transendothelial invasion assays. shLacZ and shANG TU183 cells were treated with or without $50 \mathrm{ng} / \mathrm{ml}$ EGF and CANGPTL4 for $48 \mathrm{~h}$. The total number of invading cells was quantified by Image J and images were photographed. The percentage of invading cells was determined in three independent experiments. Values are the mean \pm s.e.m. ${ }^{* *} P<0.01$; $* * * P<0.005$ 
a

(i)

\begin{tabular}{|c|c|c|c|c|}
\hline \multirow{2}{*}{ EGF } & \multicolumn{2}{|c|}{ Sc } & \multicolumn{2}{|c|}{ siANG } \\
\hline & - & + & + & + \\
\hline cANGPTL4 & - & - & - & + \\
\hline
\end{tabular}

(ii)

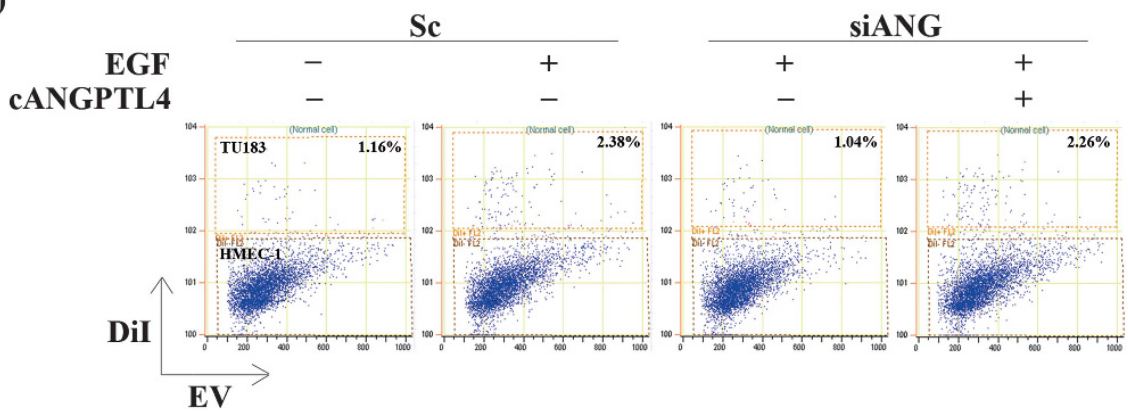

(iii)

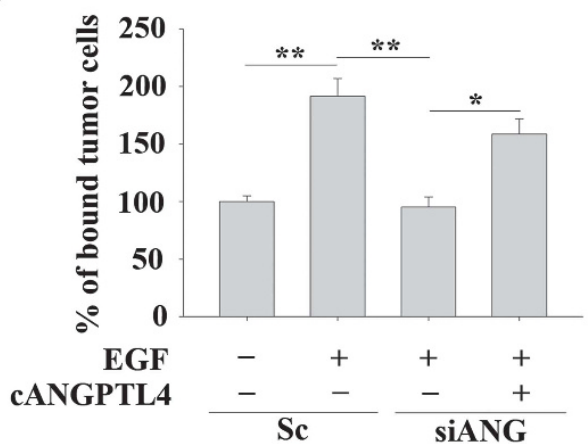

b

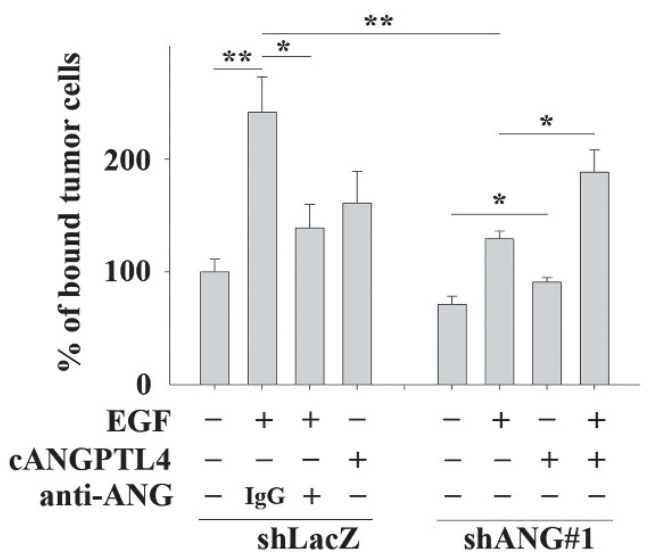

Figure 4. ANGPTL4 regulates EGF-enhanced tumour-endothelial cell interactions. (a) TU183 cells were transfected with $50 \mathrm{nM}$ ANGPTL4 siRNA oligonucleotides (siANG) and scramble siRNA (Sc) by lipofection, and the cells were treated with or without $50 \mathrm{ng} / \mathrm{ml}$ EGF and $250 \mathrm{ng} / \mathrm{ml}$ CANGPTL4 for $3 \mathrm{~h}$. The cells were then labelled with Dil and cultured with endothelial cells for 30 min. Cell attachment was examined using a microscope (i). The bound tumour cells (adherent cells) were analysed using a flow cytometer. TU183 cells were Dil-positive, and HMEC-1 cells were Dil-negative (ii). The percentage of bound tumour cells was quantified in three independent experiments by flow cytometry (iii). Values are the mean + s.e.m. (b) shLacZ and shANGPTL4 (shANG) TU183 cells were treated with or without $50 \mathrm{ng} / \mathrm{ml}$ EGF, $250 \mathrm{ng} / \mathrm{ml}$ cANGPTL4, $10 \mu \mathrm{g} / \mathrm{ml}$ anti-ANGPTL4 antibodies (anti-ANG) and $10 \mu \mathrm{g} / \mathrm{ml}$ immunoglobulin G (lgG) for $3 \mathrm{~h}$. The cells were then labelled with Dil and cultured with endothelial cells for $30 \mathrm{~min}$. The percentage of bound tumour cells was quantified in three independent experiments using a flow cytometer. Values are the mean \pm s.e.m. ${ }^{*} P<0.05 ;{ }^{*} P<0.01 ;{ }^{* *} P<0.005$

growth and increases the permeability of lung capillaries, thus enhancing lung metastasis of breast tumours. ${ }^{18,33}$ These results suggest that tumour-derived ANGPTL4 is essential for cancer metastasis.
According to our previous report ${ }^{34}$ and this study, we found that EGF-induced gene expression including PTX3 and ANGPTL4 promoted HNSCC metastasis through the induction of MMPs. The depletion of ANGPTL4 inhibited EGF-induced MMP-1, MMP-3, 
a

(i)

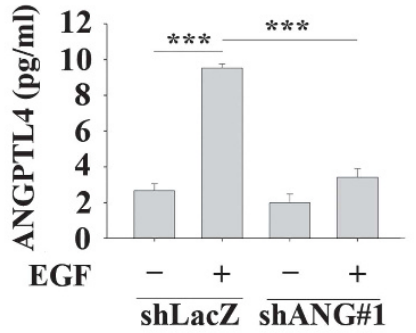

(ii)

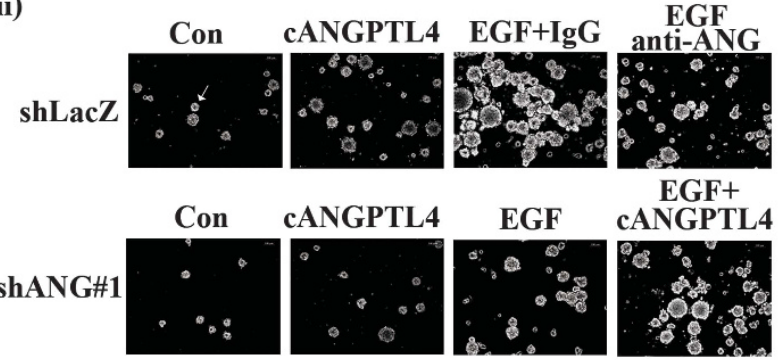

(iii)

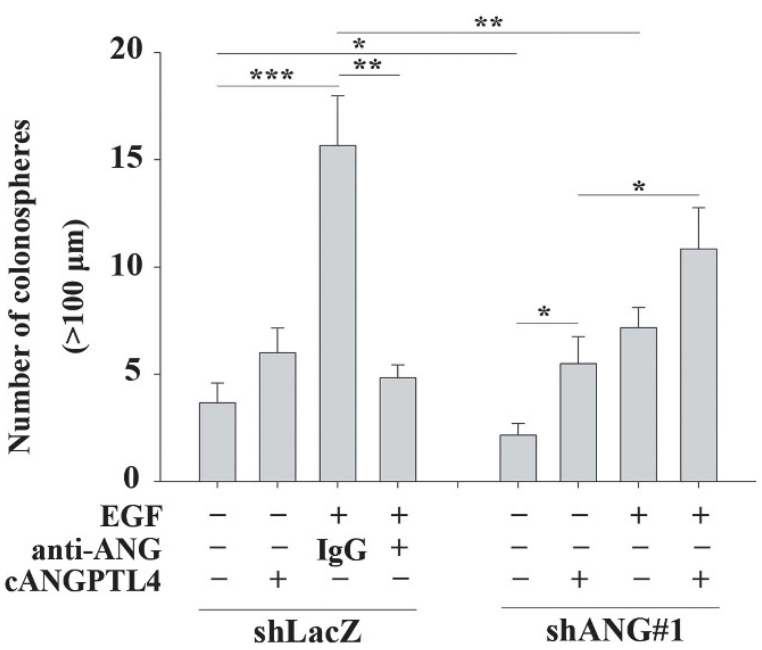

b (i)

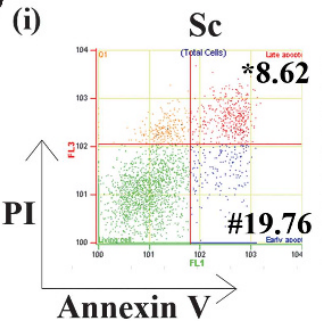

C

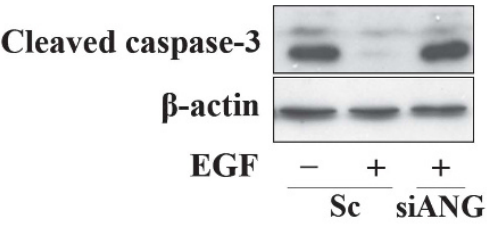

d
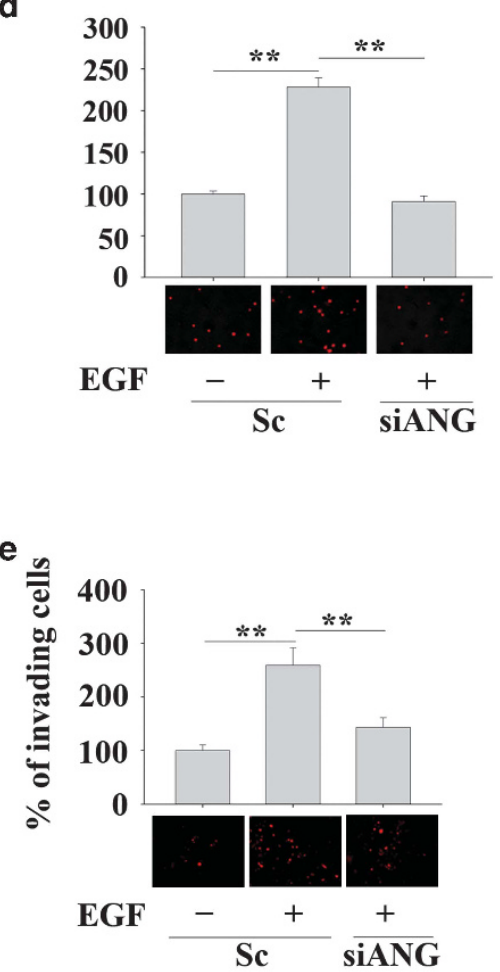

(ii)

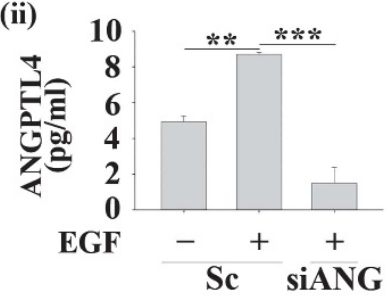

Figure 5. Expression of ANGPTL4 is essential for EGF-enhanced anoikis resistance. The anoikis resistance assay was applied as described in 'Materials and methods'. (a) Secreted ANGPTL4 from TU183 cells treated with $50 \mathrm{ng} / \mathrm{ml}$ EGF for $48 \mathrm{~h}$ was detected by ELISA (i). shLacZ and shANGPTL4 (shANG) TU183 cells were treated with or without $10 \mu \mathrm{g} / \mathrm{ml}$ anti-ANGPTL4 antibodies (anti-ANG), $10 \mu \mathrm{g} / \mathrm{ml} \mathrm{lgG}, 50 \mathrm{ng} / \mathrm{ml}$ EGF and $250 \mathrm{ng} / \mathrm{ml}$ cANGPTL4 for $48 \mathrm{~h}$. Images of colonospheres were examined using a microscope (ii). The arrow indicates a colonosphere size $>100 \mu \mathrm{m}$. Original magnification, $\times 200$. The number of colonospheres ( $>100 \mu \mathrm{m}$ ) was counted (iii). (b) TU183 cells were transfected with $50 \mathrm{nM}$ ANGPTL4 siRNA oligonucleotides (siANG) and scramble siRNA (Sc) by lipofection. Cells were treated with $50 \mathrm{ng} / \mathrm{ml}$ EGF and grown in suspension for $48 \mathrm{~h}$. Apoptotic cells were stained with Annexin V-FITC/PI and analysed by flow cytometry (i). * late apoptosis; \# early apoptosis. Secreted ANGPTL4 was detected by ELISA (ii). (c) Activation of caspase-3 was examined in EGF-treated and ANGPTL4-depleted cells and by western blotting. (d and e) TU183 cells were transfected with 50 nM ANGPTL4 siRNA oligonucleotides (siANG) and scramble siRNA (Sc) by lipofection and then grown in suspension for $48 \mathrm{~h}$. The cells were then labelled with Dil and cultured with endothelial cells for 30 min. The percentage of bound tumour cells was quantified in three independent experiments by flow cytometry (upper panel). The attachment of cells was examined using a microscope (lower panel) (d). Values are the mean \pm s.e.m. The transendothelial invasion assay was performed (e). The total number of invading cells was quantified by Image $J$ and images were photographed. The percentage of invading cells was determined in three independent experiments (upper panel). The images of invading cells were examined using a microscope (lower panel). Values are the mean \pm s.e.m. ${ }^{*} P<0.05 ;{ }^{* *} P<0.01 ;{ }^{* * *} P<0.005$. 
MMP-9 and MMP-10. However, among EGF-induced MMPs, only MMP-9 was regulated by PTX3. In addition, the induction of MMP-1 occurred earlier than MMP-9 in EGF-treated HNSCC cells. These results support the possibility that the expression of PTX3 may also be regulated by EGF-induced ANGPTL4.
Indeed, our results (unpublished data) revealed that knockdown of ANGPTL4 inhibited EGF-induced PTX3 in HNSCC, suggesting that PTX3 was one of the ANGPTL4-regulated targets. Therefore, activation of the ANGPTL4/PTX3/MMPs signalling axis was at least one of pathways involved in the

a
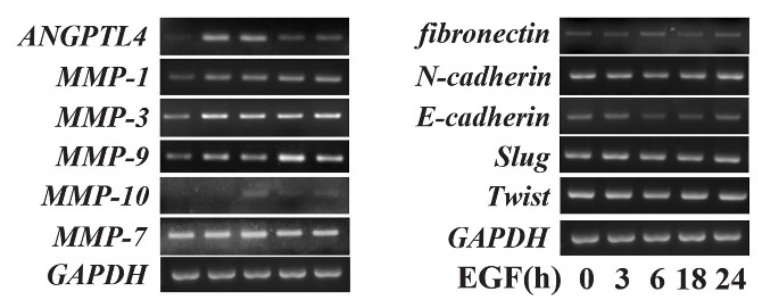

EGF(h) $0 \begin{array}{llllll} & 6 & 18 & 24\end{array}$

b

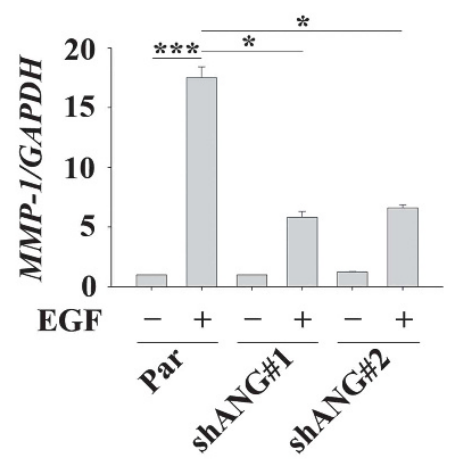

d

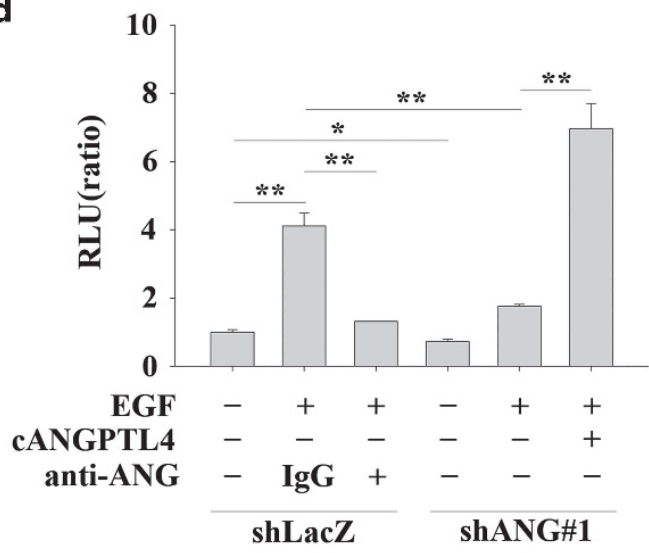

(i)

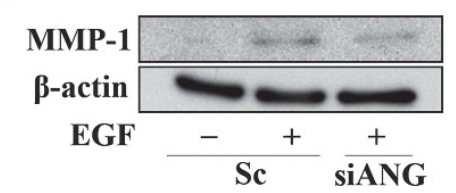

(ii)

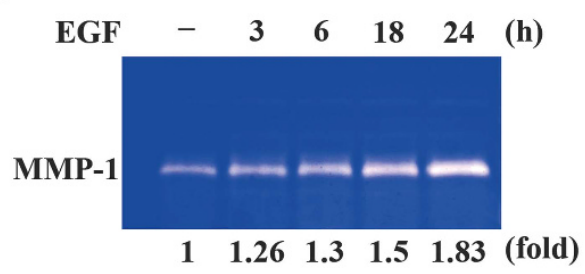

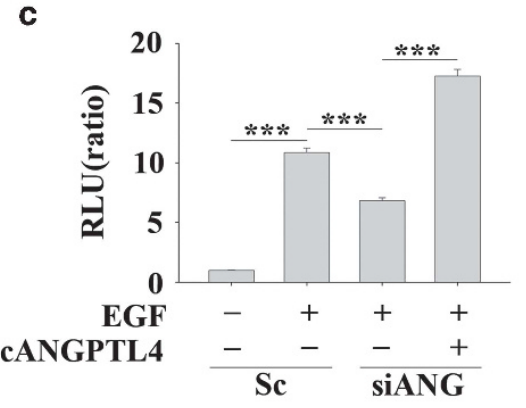


MMP-1 promoter

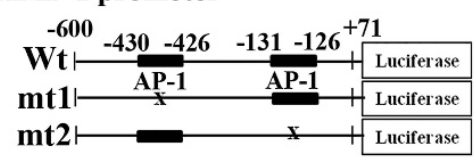

b

(i)

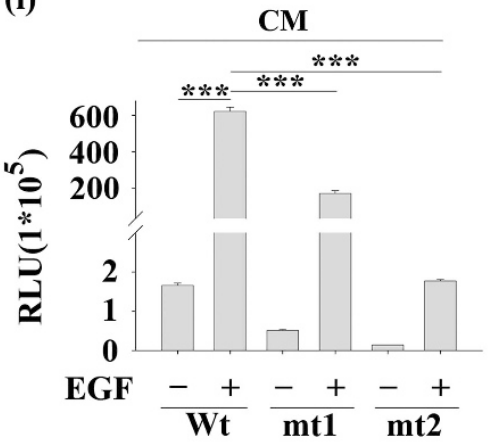

C

(i)
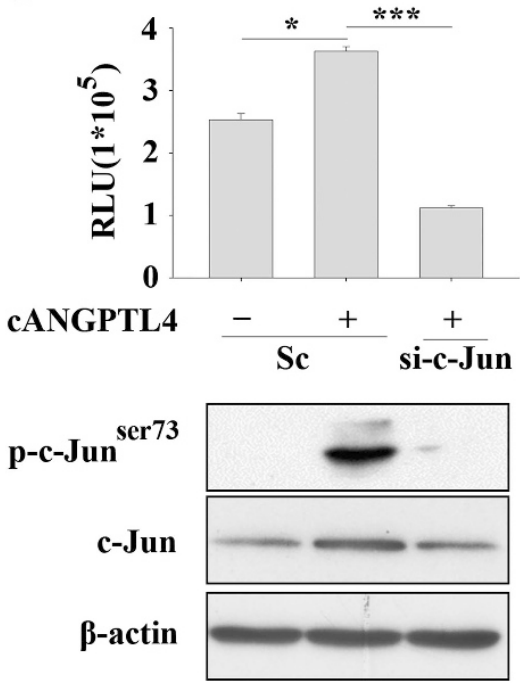

(ii)

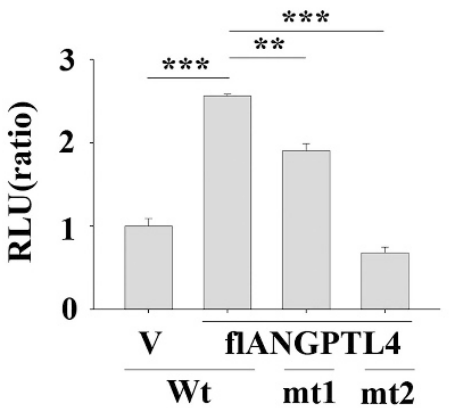

(ii)
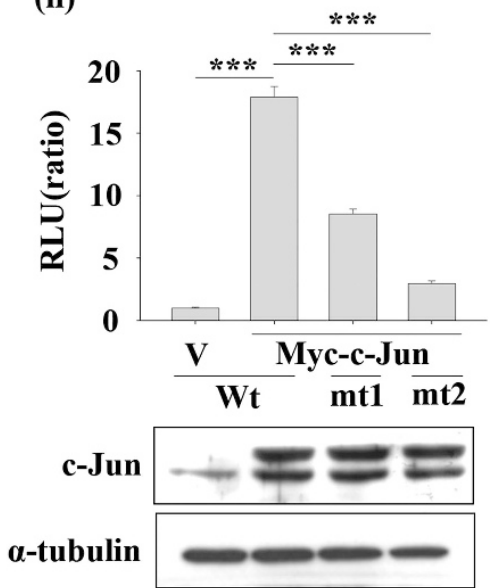

Figure 7. ANGPTL4-induced MMP-1 is dependent on c-Jun expression. (a) The MMP-1 promoter containing wild-type (Wt) and AP-1 binding site mutants (mt1 and $\mathrm{mt} 2$ ) was constructed. (b) TU183 cells were co-transfected with $0.5 \mu \mathrm{g}$ MMP-1 promoter and 20 ng renilla luciferase construct, and then treated with CM collected from EGF-treated cells (i). TU183 cells were co-transfected with $0.5 \mu \mathrm{g}$ MMP-1 promoter and $20 \mathrm{ng}$ renilla luciferase construct and $1 \mu \mathrm{g}$ flANGPTL4-expressing vector (ii). The firefly and renilla luciferase activities were then determined and normalized. Values are the mean \pm s.e.m. (c) TU183 cells were co-transfected with $0.5 \mu \mathrm{g}$ MMP-1 promoter, 20 ng renilla luciferase construct, $50 \mathrm{nM}$ c-Jun siRNA oligonucleotides, scramble siRNA (Sc) (i) and myc-c-Jun-expressing vector (ii) by lipofection and then with or without $250 \mathrm{ng} / \mathrm{ml}$ cANGPTL4 for $18 \mathrm{~h}$. The firefly and renilla luciferase activities were then determined and normalized. Values are the mean \pm s.e.m. The expression levels of c-Jun, $\beta$-actin, $\alpha$-tubulin and phosphorylated c-Jun ${ }^{\text {ser73 }}$ were analysed by western blotting. ${ }^{* * *} P<0.005$.

Figure 6. EGF-induced ANGPTL4 regulates the expression of MMP-1. (a) TU183 cells were treated with $50 \mathrm{ng} / \mathrm{ml}$ EGF for the indicated period of time. The expression levels of ANGPTL4, MMP-1, MMP-3, MMP-7, MMP-9, MMP-10, fibronectin, E-cadherin, slug, twist and GAPDH mRNA were analysed by RT-PCR and examined by $2 \%$ agarose gel electrophoresis. (b) Parental (Par) and shANGPTL4 (shANG) TU183 cells were treated with $50 \mathrm{ng} / \mathrm{ml}$ EGF for $9 \mathrm{~h}$. The expression of MMP-1 mRNA was analysed by real-time quantitative PCR. The relative levels of MMP-1 were normalized to GADPH. Values are the mean \pm s.e.m. (c) TU183 cells were co-transfected with $0.5 \mu \mathrm{g}$ MMP-1 promoter and $20 \mathrm{ng}$ renilla luciferase construct, $50 \mathrm{nM}$ ANGPTL4 siRNA oligonucleotides (siANG) and scramble siRNA (Sc) by lipofection. The cells were treated with or without $50 \mathrm{ng} / \mathrm{ml}$ EGF and $250 \mathrm{ng} / \mathrm{ml}$ cANGPTL4 for $18 \mathrm{~h}$. The firefly and renilla luciferase activities were then determined and normalized. Values are the mean \pm s.e.m. (d) shLacZ and shANGPTL4 (shANG) TU183 cells were co-transfected with $0.5 \mu \mathrm{g}$ MMP-1 promoter and $20 \mathrm{ng}$ renilla luciferase construct. Cells were pre-treated with $10 \mu \mathrm{g} / \mathrm{ml}$ of anti-ANGPTL4 antibodies (anti-ANG) and $5 \mu \mathrm{g} / \mathrm{ml} \mathrm{lgG}$ for $1 \mathrm{~h}$, and then with $50 \mathrm{ng} / \mathrm{ml}$ EGF for $18 \mathrm{~h}$. The firefly and renilla luciferase activities were then determined and normalized. Values are the mean + s.e.m. (e) TU183 cells were transfected with $50 \mathrm{nM}$ ANGPTL4 siRNA oligonucleotides (siANG) and scramble siRNA (Sc) by lipofection, and the cells were treated with or without $50 \mathrm{ng} / \mathrm{ml}$ EGF for $18 \mathrm{~h}$. The expression levels of $\beta$-actin and MMP-1 were analysed by western blotting (i). TU183 cells were treated with $50 \mathrm{ng} / \mathrm{ml} \mathrm{EGF}$ for the indicated period of time (ii). Parental (Par) and shANGPTL4 (shANG) TU183 cells were treated with $50 \mathrm{ng} / \mathrm{ml}$ EGF for $24 \mathrm{~h}$ (iii). The enzymatic activity of MMP-1 in CM was analysed using the casein-zymography assay. ${ }^{*} P<0.05 ;{ }^{* *} P<0.01$. 
a

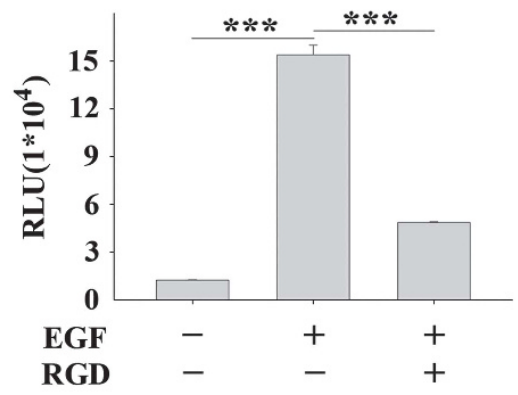

b

(i)

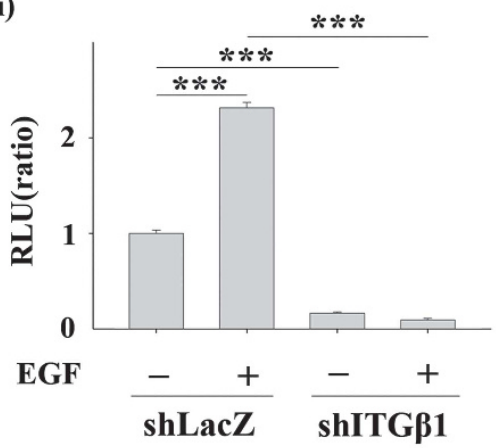

C

(i)

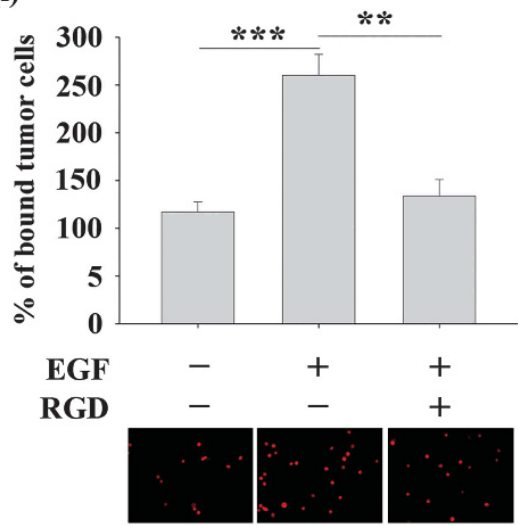

(ii)

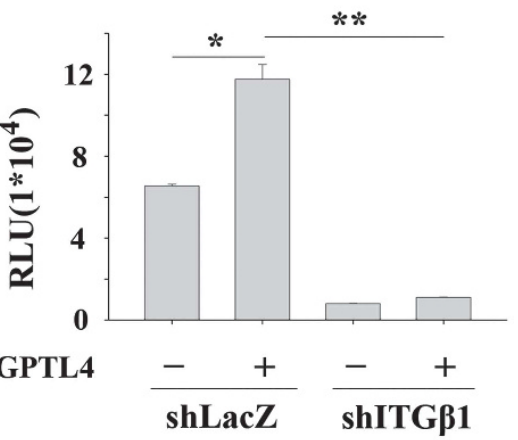

(ii)

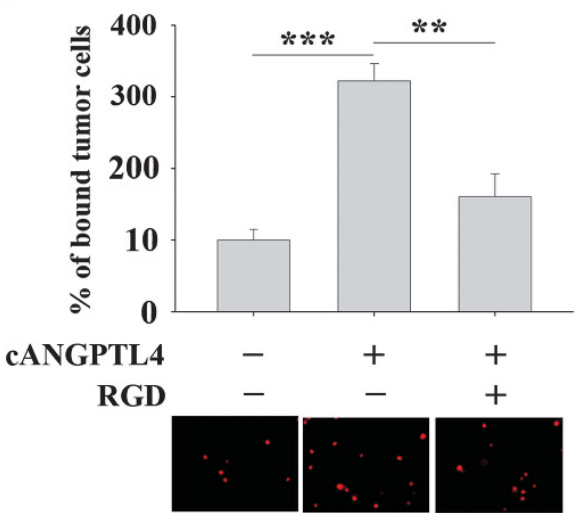

Figure 8. The activation of integrin $\beta 1$ signalling is essential for EGF- and ANGPTL4-induced MMP-1 expression and tumour-endothelial cell interactions. ( $\mathbf{a}$ and $\mathbf{b}$ ) TU183 cells were transfected with $0.5 \mu \mathrm{g}$ MMP-1 promoter and $20 \mathrm{ng}$ renilla luciferase construct and then treated with $50 \mathrm{ng} /$ $\mathrm{ml}$ EGF and $1 \mathrm{mM}$ (Arg-Gly-Asp) peptides for $18 \mathrm{~h}$ (a). shLacZ and integrin $\beta 1$-depleted (shlTG $\beta 1$ ) cells were co-transfected with $0.5 \mu \mathrm{g}$ MMP-1 promoter and $20 \mathrm{ng}$ renilla luciferase construct and then treated with $50 \mathrm{ng} / \mathrm{ml}$ EGF (i) and cANGPTL4 (250 ng/ml) (ii) for $18 \mathrm{~h}$ (b). The firefly and renilla luciferase activities were then determined and normalized. Values are the mean \pm s.e.m. (c) TU183 cells were treated with $50 \mathrm{ng} / \mathrm{ml}$ EGF (i), $250 \mathrm{ng} / \mathrm{ml}$ cANGPTL4 (ii) and $1 \mathrm{mM}$ (Arg-Gly-Asp) peptides for $3 \mathrm{~h}$. Cells were then labelled with Dil and cultured with endothelial cells for 30 min. The attachment of cells was examined using a microscope (lower panel). The percentage of bound tumour cells was quantified in three independent experiments by flow cytometry (upper panel). Values are the mean \pm s.e.m. ${ }^{*} P<0.05 ;{ }^{* *} P<0.01 ;{ }^{* * *} P<0.005$.

Figure 9. The EGF/ANGPTL4/MMP-1 axis promotes HNSCC metastasis. (a and b) TU183 cells were transfected with $50 \mathrm{nM}$ MMP-1 siRNA oligonucleotides (siMMP-1) and scramble siRNA (Sc) by lipofection and then treated with $250 \mathrm{ng} / \mathrm{ml}$ cANGPTL4 and $50 \mathrm{ng} / \mathrm{ml}$ EGF for 24 or $48 \mathrm{~h}$. To determine the percentages of migrating (a) and invading (b) cells, the cells were fixed and stained with crystal violet, solubilized with acetic acid and absorbance (OD, $595 \mathrm{~nm}$ ) was measured in a microplate reader. Values are the mean \pm s.e.m. (c) Parental (Par) TU183 cells were

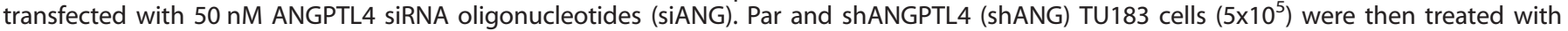
$50 \mathrm{ng} / \mathrm{ml}$ EGF for $3 \mathrm{~h}$ and then injected into the tail vein of severe combined immunodeficiency mice. Colonies in the lungs were examined and photographed at 1.5 months. Images of lung and H\&E staining (i); the tumour area was analysed using ImageJ (ii); and ANGPTL4 and MMP-1 expression were examined by IHC (iii). $n=5$ for each groups. (d) Parental (Par) and shANGPTL4 (shANG) TU183 cells were treated with $50 \mathrm{ng} / \mathrm{ml} \mathrm{EGF}$ for $3 \mathrm{~h}$ and then stained with DiO for 30 min. Cells were $\left(5 \times 10^{5}\right.$ cells $\left./ 100 \mu \mathrm{l}\right)$ injected into the tail vein of severe combined immunodeficiency mice for $24 \mathrm{~h}$ and then sacrificed for examining the metastatic tumour cells surrounding the lung tissue as described in 'Materials and methods'. The penetration of tumour cells was examined using a microscope (i). Original magnification, $\times 20$; arrows indicate the DiO-labelled tumour cells (green); Dil-labelled blood vessels (red); DAPI-labelled nucleus (blue). Tumour cells were quantified by analysing at least four sections and six fields to determine the number of tumour cells that underwent extravasation (ii). $n=5$ for each groups. Values are the mean \pm s.e.m. (e) The putative EGF/ANGPTL4/integrin $\beta 1 /$ MMP1 pathway regulates HNSCC metastasis. ${ }^{* *} P<0.01$. N.S., non signal (Non DiO-labelled signal was observed). 
regulation of EGF-induced HNSCC metastasis. In addition, ANGPTL4 and PTX3, as a lipoprotein lipase inhibitor and an inflammatory molecule, respectively, are useful biomarkers for cardiovascular disease. ${ }^{35}$ In a summary, these results provide clinical implications for PTX3 and ANGPTL4 not only in cardiovascular disease but also in HNSCC tumour metastasis. a

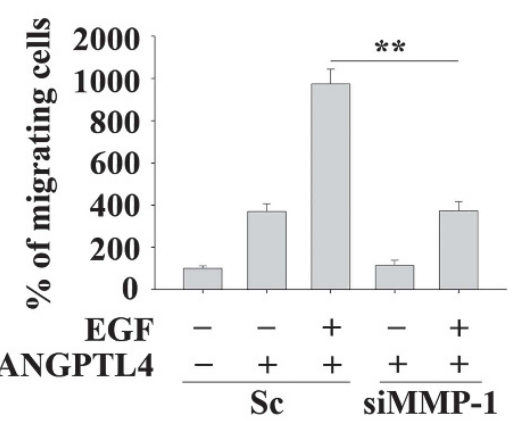

b

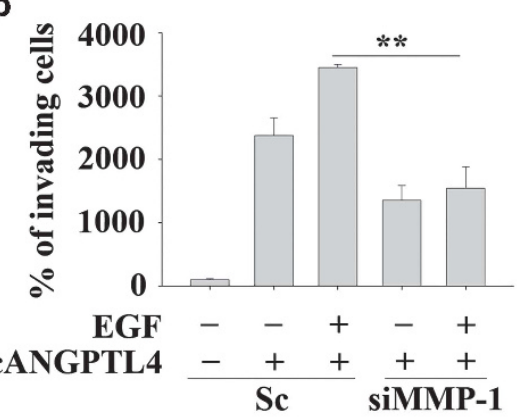

C

(i)

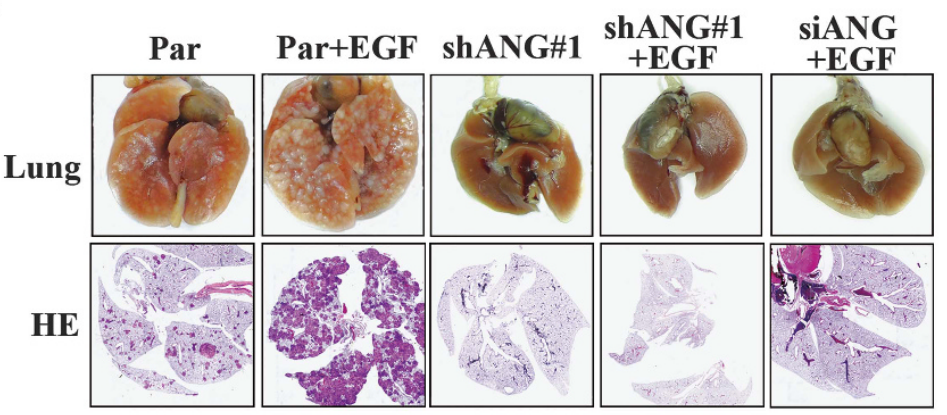

(iii)

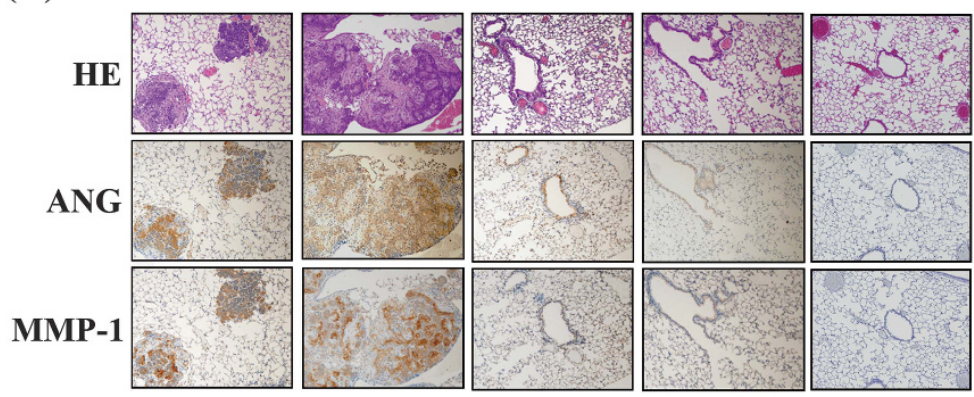

(ii)

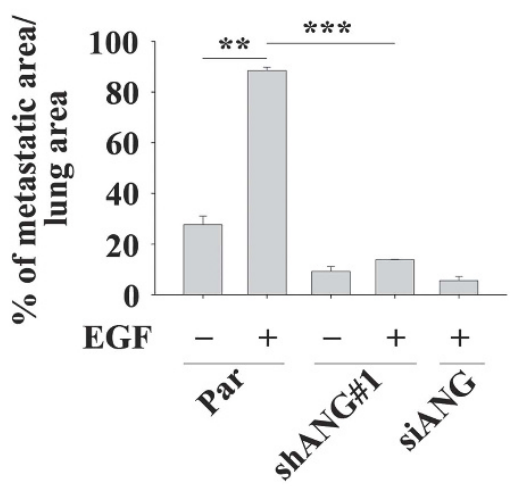

d

(i)
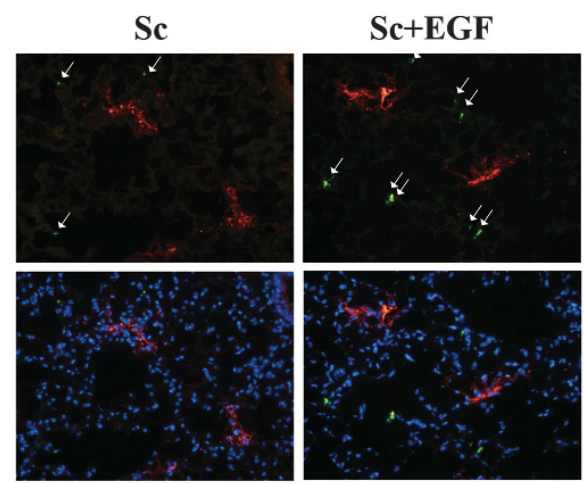

siANG+EGF
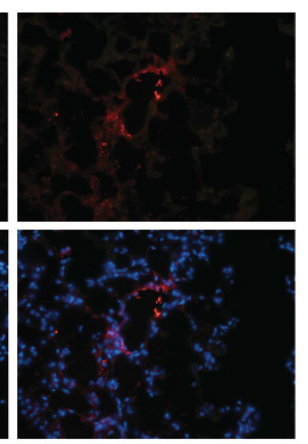

(ii)

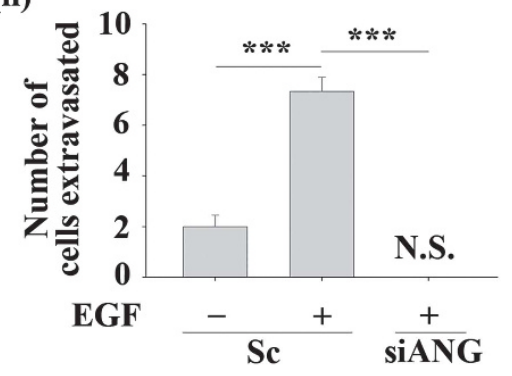

e

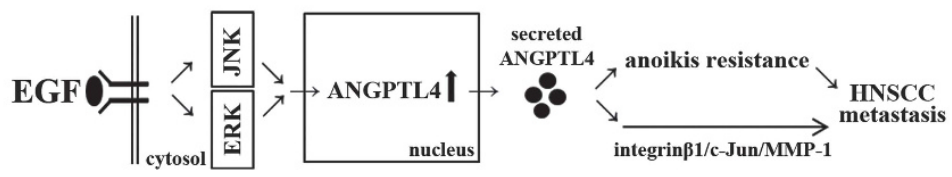


Upon entering the blood circulation, tumour cells must acquire resistance to anoikis, anchor to and finally interact with endothelial cells to successfully metastasize to distant sites. We found that EGF dramatically enhanced HNSCC anoikis resistance by inducing autocrine production of ANGPTL4. Previous studies have demonstrated that tumour-derived ANGPTL4 stimulates the production of ROS, resulting in activation of $\mathrm{Src}, \mathrm{PI} 3 \mathrm{~K} / \mathrm{PKBa}$ and ERK survival pathways to confer anoikis resistance. ${ }^{19}$ Interestingly, we found that the expression of ANGPTL4 and ROS levels were increased in anoikis resistant cells. However, depletion of ANGPTL4 dramatically reduced ROS levels in these cells (our unpublished data). These results support the possibility that the elevation of ROS levels protects against anoikis, at least in part, via EGF-induced secretion of ANGPTL4. Previous studies have demonstrated that a deficiency in ANGPTL4 activates caspase-2, $-3,-8$ and -9 activities and induces apoptosis upon anoikis in tumour cells. ${ }^{19}$ In our investigations, we clarified that ANGPTL4 participated in EGF-elicited inhibition of caspase-3 during the anchorage-independent growth of cancer cells. In addition, we found that ANGPTL4 enhanced not only tumour-endothelial cells' interactions but also invasion of anoikis-resistant cells. Taken together, these results further indicate that antioxidants may abrogate the impact of EGF-induced ANGPTL4 on circulating cancer cell survival, adhesion and invasion. Previous studies have demonstrated that ANGPTL4 disrupts endothelial junctions by activating endothelial cell integrin $\alpha 5 / \beta 1$ signalling to increase endothelial leakiness and promote breast cancer metastasis. ${ }^{29}$ Consistent with these results, we found that tumour cell integrin $\beta 1$ was required for EGF-induced MMP-1 expression and the interaction between tumour and endothelial cells. These results indicate that ANGPTL4 enhanced tumour metastasis not only by mediating vessel permeability but also by stimulating the adhesion of tumour cells to blood vessels. However, the mechanism involved in ANGPTL4-mediated stimulation of tumour-endothelial cell interaction remains to be clarified. We also cannot rule out the possibility that the activation of integrin $a 5 / \beta 1$ signalling in endothelial cells may also contribute to their interaction with tumour cells in response to EGF-induced ANGPTL4.

ANGPTL4 directly affects communication between cells and the extracellular matrix by altering the availability of intact matrix proteins during keratinocyte wound healing. ${ }^{36}$ Previous studies have shown that the co-expression of ANGPTL4 and MMPs correlated with cancer invasion and metastasis. ${ }^{23,24}$ Although ANGPTL4 has been reported to enhance the expression of MMP-1 and MMP-3, 25,26 the mechanism involved in regulating MMP-1 expression remains unclear. In this study, we clarified that ANGPTL4-induced MMP-1 expression was mediated by the integrin $\beta 1 / c-J u n$ signalling pathway. The AP- 1 binding sites located in the MMP-1 promoter region were essential for the activation of the promoter by EGF-induced ANGPTL4. These results indicate that a down-stream component of the integrin $\beta 1$ signalling pathway, such as c-Jun, is required for the up-regulation of MMP-1 gene expression, resulting in the promotion of tumour invasion. The enhancement of ANGPTL4 expression has been reported in many tissues. For example, ANGPTL4 is highly expressed in human liver, adipose tissue, blood plasma, placenta, small intestine and heart. ${ }^{37,38}$ ANGPTL4 mRNA has been found to be up-regulated in tumours including clear cell renal carcinomas, oral tongue squamous cell carcinomas and human gastric cancers. $^{39,40}$ The up-regulation of ANGPTL4 could be mediated by several endogenous cytokines, such as $\mathrm{PGE}_{2}$ and TGF $\beta$. In addition to these cytokines, we further clarified that EGF also enhanced ANGPTL4 expression and secretion, resulting in HNSCC metastasis. In contrast to the function of cytokineinduced ANGPTL4 in promoting tumorigenesis, overexpression of ANGPTL4 in cells has been reported to down-regulate tumour metastasis. For example, ANGPTL4 prevents the metastasis of
Lewis lung carcinoma $3 \mathrm{LL}$ cells by inhibiting tumour cell intravasation from the primary tumour to lymphatic or blood vessels. ${ }^{22}$ The inhibition of tumour metastasis by ANGPTL4 was mediated by the suppression of vascular tube formation in the tumour microenvironment. ${ }^{21}$ Although the effect of ANGPTL4 on tumour metastasis is still controversial, these results suggest that the differential functions of ANGPTL4 may be dependent on its induction by endogenous cytokines such as EGF and TGF $\beta$, or the overexpression of ANGPTL4.

In conclusion, we demonstrated the biological functions of ANGPTL4 in EGF-induced HNSCC metastasis. As shown in Figure 9e, EGF induced ANGPTL4 expression by activating the JNK and ERK pathways (our unpublished data). Autocrine production of ANGPTL4 further activated the integrin $\beta 1 / \mathrm{c}$-Jun signalling pathway to enhance MMP-1 expression. Our results show that the induction of ANGPTL4 not only enhances anoikis resistance and tumour-endothelial cell interactions, but also up-regulates MMP-1 expression to promote the metastatic seeding of tumour cells in the lungs. Measurement of ANGPTL4 expression levels may provide prognostic information regarding HNSCC metastasis, which suggests that ANGPTL4 could be a novel therapeutic target for EGFRoverexpressing HNSCC.

\section{MATERIALS AND METHODS}

\section{Cell culture}

The FaDu head and neck cancer cell line was purchased from the American Type Culture Collection (ATCC, Manassas, VA, USA). The human microvascular endothelial cell line (HMEC-1) was kindly provided by Dr Trai-Ming Yeh (Department of Medical Laboratory Science and Biotechnology, College of Medicine, National Cheng Kung University, Tainan, Taiwan). The head and neck cancer cell lines TU183, UMSCC1 and SAS were kindly provided by Dr Kwang-Yu Chang (National Health Research Institutes, NHRI, Taiwan). ${ }^{41}$ These head and neck cancer cell lines were maintained at $37^{\circ} \mathrm{C}$ with $5 \% \mathrm{CO}_{2}$ in $10-\mathrm{cm}$ plastic dishes containing $7 \mathrm{ml}$ of Dulbecco's Modified Eagle's Medium (Invitrogen, Grand Island, NY, USA) supplemented with $10 \%$ fetal bovine serum (Invitrogen), $100 \mu \mathrm{g} / \mathrm{ml}$ streptomycin (Invitrogen) and 100 units $/ \mathrm{ml}$ penicillin (Invitrogen). The FaDu cell line was maintained at $37^{\circ} \mathrm{C}$ with $5 \% \mathrm{CO}_{2}$ in $10-\mathrm{cm}$ plastic dishes containing $10 \mathrm{ml}$ of Eagle's Minimum Essential Medium (Invitrogen) supplemented with 10\% fetal bovine serum, $100 \mu \mathrm{g} / \mathrm{ml}$ streptomycin and $100 \mathrm{units} / \mathrm{ml}$ penicillin. The HMEC-1 cells were maintained in MCDB131 culture medium (Sigma-Aldrich, St Louis, MO, USA) supplemented with $10 \%$ fetal bovine serum, $100 \mu \mathrm{g} / \mathrm{ml}$ streptomycin, 100 units $/ \mathrm{ml}$ penicillin and $15 \mu \mathrm{g} / \mathrm{ml}$ endothelial cell growth supplement (Millipore, Bedford, MA, USA).

\section{Conditioned medium and antibodies}

Full details are available in Supplementary Materials and Methods.

Reverse transcription-PCR and real-time quantitative RT-PCR Full details are available in Supplementary Materials and Methods.

\section{Enzyme-linked immunosorbent assay}

Full details are available in Supplementary Materials and Methods.

\section{Knockdown experiments}

Full details are available in Supplementary Materials and Methods.

Transfection with siRNA oligonucleotides

Full details are available in Supplementary Materials and Methods.

Migration and invasion assay

Full details are available in Supplementary Materials and Methods. 
Transendothelial invasion assay

Full details are available in Supplementary Materials and Methods.

Cell adhesion assay

Briefly, tumour cells were treated with $50 \mathrm{ng} / \mathrm{ml}$ of EGF or $250 \mathrm{ng} / \mathrm{ml}$ of CANGPTRL4 for $3 \mathrm{~h}$ and then labelled for $30 \mathrm{~min}$ at $37{ }^{\circ} \mathrm{C}$ with Dil (Invitrogen Life Technologies, Carlsbad, CA, USA) and washed twice with phosphate-buffered saline. The tumour cells $\left(1 \times 10^{5}\right.$ cells $\left./ \mathrm{ml}\right)$ were resuspended and added to a monolayer of HMEC-1 cells. After incubation for $30 \mathrm{~min}$ at $37^{\circ} \mathrm{C}$, the wells were gently washed twice with phosphatebuffered saline to remove non-adherent cells. The cells were photographed and the number of adherent tumour cells and HMEC-1 cells was quantified by Cell Lab Quanta SC flow cytometry (Beckman Coulter, Fullerton, CA, USA) equipped with an argon laser. The Dil emission was measured at $575 \mathrm{~nm}$ (FL2) and the data was analysed by FlowJo software (Treestar, Inc., San Carlos, CA, USA). The percentage of bound tumour cells was determined by the ratio of the bound tumour cells (adherent cells) that were Dil-positive to the HMEC-1 cells that were Dil-negative $\left(5 \times 10^{3}\right.$ cells per group).

\section{Anoikis assay}

Cells were seeded and grown on polyHEMA (Sigma)-coated plates in 6-cm plastic dishes containing $3 \mathrm{ml}$ of Dulbecco's Modified Eagle's Medium (Invitrogen) supplemented with 10\% fetal bovine serum (Invitrogen) and $1 \%$ penicillin-streptomycin-glutamine. Next, they were treated with or without EGF, CANGPTL4 and ANGPTL4 antibody for $48 \mathrm{~h}$. Samples were analysed in a Cell Lab Quanta SC flow cytometry (Beckman Coulter) equipped with an argon laser and the data was analysed by FlowJo software (Treestar). Ten thousand events were collected for each sample. For the analysis of cell death, cells were harvested and then washed with PBS. $1 \times 10^{5}$ cells were resuspended in $100 \mu$ l binding buffer containing Annexin V-FITC (1:100) (BD Pharmingen, San Diego, CA, USA) and propidium iodide (1:2000, BD Pharmingen) for $15 \mathrm{~min}$ at room temperature and then determined by flow cytometer.

Luciferase assays and plasmid construction

Full details are available in Supplementary Materials and Methods.

\section{Tumour metastasis assay in an animal model}

Tumour metastasis was determined by tail vein intravenous injection of cancer cells into 6- to 8-week-old male severe combined immunodeficiency mice. There is no randomization method and blinding group for allocation of animals. Briefly, $5 \times 10^{5}$ tumour cells were resuspended in $100 \mu \mathrm{l}$ with Hank's Balanced Salt Solution and then injected into the tail vein of mice. To evaluate lung metastasis, mice were sacrificed up to 1.5 months after injection. H\&E staining was performed by the Human Biobank, Research Center of Clinical Medicine, NCKU Hospital. For the lung extravasation assay, 3,3'-dioctadecyloxacarbocyanine perchlorate (DiO) labelled cells were injected into the tail vein of mice and then sacrificed up to $24 \mathrm{~h}$ after injection. The blood vessels were directly labelled by cardiac perfusion using a specially formulated aqueous solution containing 1,1'-dioctadecyl-3,3,3',3'-tetramethylindocarbocyanine perchlorate (Dil), which incorporates into endothelial cell membranes upon contact. ${ }^{31}$ Lung tissues of mice were cryosectioned $(8 \mu \mathrm{m})$ for fluorescence imaging to visualize the vasculature (red) and tumour cells (green). ${ }^{30}$ Quantification was performed by analysing at least four sections and six fields to determine the number of tumour cells that underwent extravasation. All mice were obtained from the National Cheng Kung University (NCKU) Laboratory Animal Center (Tainan, Taiwan). All animal experiments in this study were approved (Approved No. NCKU-IACUC-102-078) by the Laboratory Animal Committee of NCKU.

\section{Statistical analysis}

Data are expressed as the means \pm s.e.m. The statistical analysis was performed using SigmaPlot version 10.0 for Microsoft Windows, and an independent-samples $t$-test was used for comparisons between two groups. Centre values indicate as mean. A $P$-value less than 0.05 was considered significant and denoted by *. P-values less than 0.01 and 0.001 are denoted by ${ }^{* *}$ and ${ }^{* * *}$, respectively.

\section{CONFLICT OF INTEREST}

The authors declare no conflict of interest.

\section{ACKNOWLEDGEMENTS}

This work was supported by the Ministry of Science and Technology of Taiwan [Grant NSC 102-2628-B-006- 011-MY3; MOST 105-2320-B-006-022-MY3]; and National Cheng Kung University [the Headquarters of University Advancement]. We thank for the kind gift of MMP-1 gene promoter-PGL3 from Dr Ju-Ming Wang.

\section{REFERENCES}

1 Siegel R, Naishadham D, Jemal A. Cancer statistics. 2013. CA Cancer J Clin 2013; 63: $11-30$.

2 Carvalho AL, Nishimoto IN, Califano JA, Kowalski LP. Trends in incidence and prognosis for head and neck cancer in the United States: a site-specific analysis of the SEER database. Int J Cancer 2005; 114: 806-816.

3 Fidler IJ. The pathogenesis of cancer metastasis: the 'seed and soil' hypothesis revisited. Nat Rev Cancer 2003; 3: 453-458.

4 Simpson CD, Anyiwe K, Schimmer AD. Anoikis resistance and tumor metastasis. Cancer Lett 2008; 272: 177-185.

5 Frisch SM, Francis H. Disruption of epithelial cell-matrix interactions induces apoptosis. J Cell Biol 1994; 124: 619-626.

6 Paoli P, Giannoni E, Chiarugi P. Anoikis molecular pathways and its role in cancer progression. Biochim Biophys Acta 2013; 1833: 3481-3498.

7 Humtsoe JO, Kramer RH. Differential epidermal growth factor receptor signaling regulates anchorage-independent growth by modulation of the PI3K/AKT pathway. Oncogene 2010; 29: 1214-1226.

8 Zeng Q, Chen S, You Z, Yang F, Carey TE, Saims D et al. Hepatocyte growth factor inhibits anoikis in head and neck squamous cell carcinoma cells by activation of ERK and Akt signaling independent of NFkappa B. J Biol Chem 2002; 277: 25203-25208.

9 Shen X, Kramer RH. Adhesion-mediated squamous cell carcinoma survival through ligand-independent activation of epidermal growth factor receptor. Am J Pathol 2004; 165: 1315-1329.

10 Dawson JC, Timpson P, Kalna G, Machesky LM. Mtss1 regulates epidermal growth factor signaling in head and neck squamous carcinoma cells. Oncogene 2012; 31: 1781-1793.

11 Zuo JH, Zhu W, Li MY, Li XH, Yi H, Zeng GQ et al. Activation of EGFR promotes squamous carcinoma SCC10A cell migration and invasion via inducing EMT-like phenotype change and MMP-9-mediated degradation of E-cadherin. J Cell Biochem 2011; 112: 2508-2517.

12 Masuelli L, Budillon A, Marzocchella L, Mrozek MA, Vitolo D, Di Gennaro E et al. Caveolin-1 overexpression is associated with simultaneous abnormal expression of the E-cadherin/alpha-beta catenins complex and multiple ErbB receptors and with lymph nodes metastasis in head and neck squamous cell carcinomas. J Cell Physiol 2012; 227: 3344-3353.

13 Xiao YC, Yang ZB, Cheng XS, Fang XB, Shen T, Xia CF et al. CXCL8, overexpressed in colorectal cancer, enhances the resistance of colorectal cancer cells to anoikis. Cancer Lett 2015; 361: 22-32.

14 Oike Y, Akao M, Kubota Y, Suda T. Angiopoietin-like proteins: potential new targets for metabolic syndrome therapy. Trends Mol Med 2005; 11: 473-479.

15 Katanasaka Y, Kodera Y, Kitamura Y, Morimoto T, Tamura T, Koizumi F. Epidermal growth factor receptor variant type III markedly accelerates angiogenesis and tumor growth via inducing c-myc mediated angiopoietin-like 4 expression in malignant glioma. Mol Cancer 2013; 12: 31.

16 Kim SH, Park YY, Kim SW, Lee JS, Wang D, DuBois RN. ANGPTL4 induction by prostaglandin E2 under hypoxic conditions promotes colorectal cancer progression. Cancer Res 2011; 71: 7010-7020.

17 Tanaka J, Irie T, Yamamoto G, Yasuhara R, Isobe T, Hokazono C et al. ANGPTL4 regulates the metastatic potential of oral squamous cell carcinoma. J Oral Pathol Med 2015; 44: 126-133.

18 Padua D, Zhang XH, Wang Q, Nadal C, Gerald WL, Gomis RR et al. TGFbeta primes breast tumors for lung metastasis seeding through angiopoietin-like 4. Cell 2008; 133: 66-77.

19 Terada LS, Nwariaku FE. Escaping anoikis through ROS: ANGPTL4 controls integrin signaling through Nox1. Cancer Cell 2011; 19: 297-299.

20 Minn AJ, Gupta GP, Siegel PM, Bos PD, Shu W, Giri DD et al. Genes that mediate breast cancer metastasis to lung. Nature 2005; 436: 518-524.

21 Okochi-Takada E, Hattori N, Tsukamoto T, Miyamoto K, Ando T, Ito S et al. ANGPTL4 is a secreted tumor suppressor that inhibits angiogenesis. Oncogene 2014; 33: 2273-2278.

22 Galaup A, Cazes A, Le Jan S, Philippe J, Connault E, Le Coz E et al. Angiopoietin-like 4 prevents metastasis through inhibition of vascular permeability and tumor cell motility and invasiveness. Proc Natl Acad Sci USA 2006; 103: 18721-18726. 
23 Akishima-Fukasawa Y, Ishikawa Y, Akasaka Y, Uzuki M, Inomata N, Yokoo T et al. Histopathological predictors of regional lymph node metastasis at the invasive front in early colorectal cancer. Histopathology 2011; 59: 470-481.

24 Sun Y, Long J, Zhou Y. Angiopoietin-like 4 promotes melanoma cell invasion and survival through aldolase A. Oncol Lett 2014; 8: 211-217.

25 Murata M, Yudo K, Nakamura H, Chiba J, Okamoto K, Suematsu N et al. Hypoxia upregulates the expression of angiopoietin-like-4 in human articular chondrocytes: role of angiopoietin-like- 4 in the expression of matrix metalloproteinases and cartilage degradation. J Orthop Res 2009; 27: 50-57.

26 Mathieu M, lampietro M, Chuchana P, Guerit D, Djouad F, Noel D et al. Involvement of angiopoietin-like 4 in matrix remodeling during chondrogenic differentiation of mesenchymal stem cells. J Biol Chem 2014; 289: 8402-8412.

27 Kuo TC, Tan CT, Chang YW, Hong CC, Lee WJ, Chen MW et al. Angiopoietin-like protein 1 suppresses SLUG to inhibit cancer cell motility. J Clin Invest 2013; 123: 1082-1095.

28 Kimura R, Ishikawa C, Rokkaku T, Janknecht R, Mori N. Phosphorylated c-Jun and Fra-1 induce matrix metalloproteinase- 1 and thereby regulate invasion activity of 143B osteosarcoma cells. Biochim Biophys Acta 2011; 1813: 1543-1553.

29 Huang RL, Teo Z, Chong HC, Zhu P, Tan MJ, Tan CK et al. ANGPTL4 modulates vascular junction integrity by integrin signaling and disruption of intercellular VEcadherin and claudin-5 clusters. Blood 2011; 118: 3990-4002.

30 Tichet M, Prod'Homme V, Fenouille N, Ambrosetti D, Mallavialle A, Cerezo M et al. Tumour-derived SPARC drives vascular permeability and extravasation through endothelial VCAM1 signalling to promote metastasis. Nat Commun 2015; 6: 6993.

31 Li Y, Song Y, Zhao L, Gaidosh G, Laties AM, Wen R. Direct labeling and visualization of blood vessels with lipophilic carbocyanine dye Dil. Nat Protoc 2008; 3: 1703-1708.

32 Al-Mehdi AB, Tozawa K, Fisher AB, Shientag L, Lee A, Muschel RJ. Intravascular origin of metastasis from the proliferation of endothelium-attached tumor cells: a new model for metastasis. Nat Med 2000; 6: 100-102.

33 Zhu P, Tan MJ, Huang RL, Tan CK, Chong HC, Pal M et al. Angiopoietin-like 4 protein elevates the prosurvival intracellular $\mathrm{O} 2(-): \mathrm{H} 2 \mathrm{O} 2$ ratio and confers anoikis resistance to tumors. Cancer Cell 2011; 19: 401-415.

34 Chang WC, Wu SL, Huang WC, Hsu JY, Chan SH, Wang JM et al. PTX3 gene activation in EGF-induced head and neck cancer cell metastasis. Oncotarget 2015; 6: 7741-7757.
35 Maekawa Y, Nagai T, Anzai A. Pentraxins: CRP and PTX3 and cardiovascular disease. Inflamm Allergy Drug Targets 2011; 10: 229-235.

36 Goh YY, Pal M, Chong HC, Zhu P, Tan MJ, Punugu L et al. Angiopoietin-like 4 interacts with matrix proteins to modulate wound healing. J Biol Chem 2010; 285: 32999-33009.

37 Mandard S, Zandbergen F, van Straten E, Wahli W, Kuipers F, Muller M et al. The fasting-induced adipose factor/angiopoietin-like protein 4 is physically associated with lipoproteins and governs plasma lipid levels and adiposity. J Biol Chem 2006; 281: 934-944.

38 Kersten S, Lichtenstein L, Steenbergen E, Mudde K, Hendriks HF, Hesselink MK et al. Caloric restriction and exercise increase plasma ANGPTL4 levels in humans via elevated free fatty acids. Arterioscler Thromb Vasc Biol 2009; 29: 969-974.

39 Nakayama T, Hirakawa H, Shibata K, Nazneen A, Abe K, Nagayasu T et al. Expression of angiopoietin-like 4 (ANGPTL4) in human colorectal cancer: ANGPTL4 promotes venous invasion and distant metastasis. Oncol Rep 2011; 25: 929-935

40 Le Jan S, Amy C, Cazes A, Monnot C, Lamande N, Favier J et al. Angiopoietin-like 4 is a proangiogenic factor produced during ischemia and in conventional renal cell carcinoma. Am J Pathol 2003; 162: 1521-1528.

41 Chang KY, Tsai SY, Wu CM, Yen CJ, Chuang BF, Chang JY. Novel phosphoinositide 3-kinase/mTOR dual inhibitor, NVP-BGT226, displays potent growth-inhibitory activity against human head and neck cancer cells in vitro and in vivo. Clin Cancer Res 2011; 17: 7116-7126.

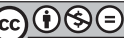

This work is licensed under a Creative Commons AttributionNonCommercial-NoDerivs 4.0 International License. The images or other third party material in this article are included in the article's Creative Commons license, unless indicated otherwise in the credit line; if the material is not included under the Creative Commons license, users will need to obtain permission from the license holder to reproduce the material. To view a copy of this license, visit http:// creativecommons.org/licenses/by-nc-nd/4.0/

(c) The Author(s) 2017

Supplementary Information accompanies this paper on the Oncogene website (http://www.nature.com/onc) 